\title{
Computational and Experimental Study of Turbulent Flow in a 0.4-Scale Water Model of a Continuous Steel Caster
}

\begin{abstract}
QUAN YUAN, SIVARAJ SIVARAMAKRISHNAN, S.P. VANKA, and B.G. THOMAS
Single-phase turbulent flow in a 0.4-scale water model of a continuous steel caster is investigated using large eddy simulations (LES) and particle image velocimetry (PIV). The computational domain includes the entire submerged entry nozzle (SEN) starting from the tundish exit and the complete mold region. The results show a large, elongated recirculation zone in the SEN below the slide gate. The simulation also shows that the flow exiting the nozzle ports has a complex time-evolving pattern with strong cross-stream velocities, which is also seen in the experiments. With a few exceptions, which are probably due to uncertainties in the measurements, the computed flow field agrees with the measurements. The instantaneous jet is seen to have two typical patterns: a wobbling "stair-step" downward jet and a jet that bends upward midway between the SEN and the narrow face. A 51second time average suppressed the asymmetries between the two halves of the upper mold region. However, the instantaneous velocity fields can be very different in the two halves. Long-term flow asymmetry is observed in the lower region. Interactions between the two halves cause large velocity fluctuations near the top surface. The effects of simplifying the computational domain and approximating the inlet conditions are presented.
\end{abstract}

\section{INTRODUCTION}

TURBULENT flow in the mold region of continuous steel casters is associated with costly failures (e.g., shell-thinning breakout) and the formation of many defects (e.g., slivers) by affecting important phenomena such as top-surface-levelfluctuations and the transport of impurity particles and superheat. ${ }^{[1-4]}$ Understanding the unsteady flow structures in this process is an important step in avoiding failures and decreasing defects. Unfortunately, because of the high temperature $(\sim 1800 \mathrm{~K})$ of superheated steel, it is difficult to conduct velocity measurements directly in molten steel. ${ }^{[5]}$ However, due to the nearly equal kinematic viscosities of molten steel and water, water models have been extensively used to investigate the flow in steel casters. ${ }^{[6-11]}$

The dimensions and operating conditions of a water model are usually chosen to have geometry and Froude number (or sometimes Reynolds number) similarities ${ }^{[12]}$ with the actual steel caster. Figure 1(a) shows an example of a scaled water model. ${ }^{[9,13]}$ The walls of the tundish, the nozzle, and the mold of a water model are usually made of transparent plastic plates. The mold side walls are sometimes curved to represent the tapering shape of the internal liquid cavity within the solidifying steel shell. A slide gate (Figure 1(a)) or stopper rod is used to control the flow rate by adjusting the opening area in order to achieve the desired casting speed (defined as the downward withdrawal speed of the shell in an actual steel caster). Water flows downward from the tundish, passes through the nozzle, enters the mold cavity, and exits from

QUAN YUAN, Ph.D. Candidate, S.P. VANKA, Professor, and B.G. THOMAS, W. Grafton and Lillian B. Wilkins Professor, are with the Department of Mechanical and Industrial Engineering, University of Illinois at Urbana-Champaign, Urbana, IL 61801. Contact e-mail: bgthomas@uiuc.edu SIVARAJ SIVARAMAKRISHNAN, Ph.D. Candidate, is with the Biomedical Engineering Department, Northwestern University, Evanston, IL 60208.

Manuscript submitted July 23, 2001. outlet ports near the bottom. It should be mentioned that two main differences exist between a water model and its corresponding steel caster. First, in the mold region, the no-slip solid wall of a water model does not represent the solidification occurring at the shell front. Second, a water model has a horizontal bottom plate with outlet ports, while in a continuous steel caster, molten steel flows into a tapering section resulting from the solidification. Despite these differences, however, our recent studies have confirmed that the velocity field in a water model generally agrees with that in a steel caster, especially in the top region. ${ }^{[14]}$

One of the advantages of a water model is that its transparent walls allow flow visualization such as dye injection ${ }^{[14,15]}$ (Figure 19) and the penetration of laser light. This enables the use of accurate and nonintrusive optical laser velocimetry techniques. ${ }^{[16]}$ Two typical methods are laser-doppler velocimetry (LDV) ${ }^{[16,17]}$ and particle image velocimetry (PIV). ${ }^{[16,18]}$ The LDV technique measures instantaneous flow velocities at single or multiple points by detecting the Doppler frequency shift of the laser light, ${ }^{[16]}$ while PIV is a method designed for measuring an instantaneous planar velocity field. ${ }^{[16]}$ During PIV measurements, a pulsed laser sheet is used to illuminate a desired planar section through the flow field, where small particles (usually 1 to $20 \mu \mathrm{m}$ ) are seeded into and well mixed with the fluid. A charge coupled device (CCD) camera is used to record the images of the illuminated particles in the flow field. The time interval between two consecutive laser pulses, which produce a pair of exposures, is only a few microseconds. The particle images are then discretized into rectangular interrogation areas and the particle positions are correlated to produce a spatially averaged displacement vector. By dividing the displacement vector by the laser pulse time interval for each interrogation area, an instantaneous velocity field is obtained. This procedure is repeated at $\sim 1$-second time intervals to measure the evolution of a flow field. Computers have so improved the simplicity and speed of this method that it is now often called digital PIV (DPIV) ${ }^{[19]}$ Details on PIV can be found elsewhere. ${ }^{[16,18]}$ 
Numerical simulation is another powerful tool used to study turbulent flow in continuous casting. Models of turbulent flow can be classified into the Reynolds-averaged approach, large eddy simulation (LES) and direct numerical simulation (DNS). ${ }^{[20]}$ Because of its low computational cost, the Reynolds-averaged approach, typically with the two-equation $(\mathrm{k}-\varepsilon)$ turbulence
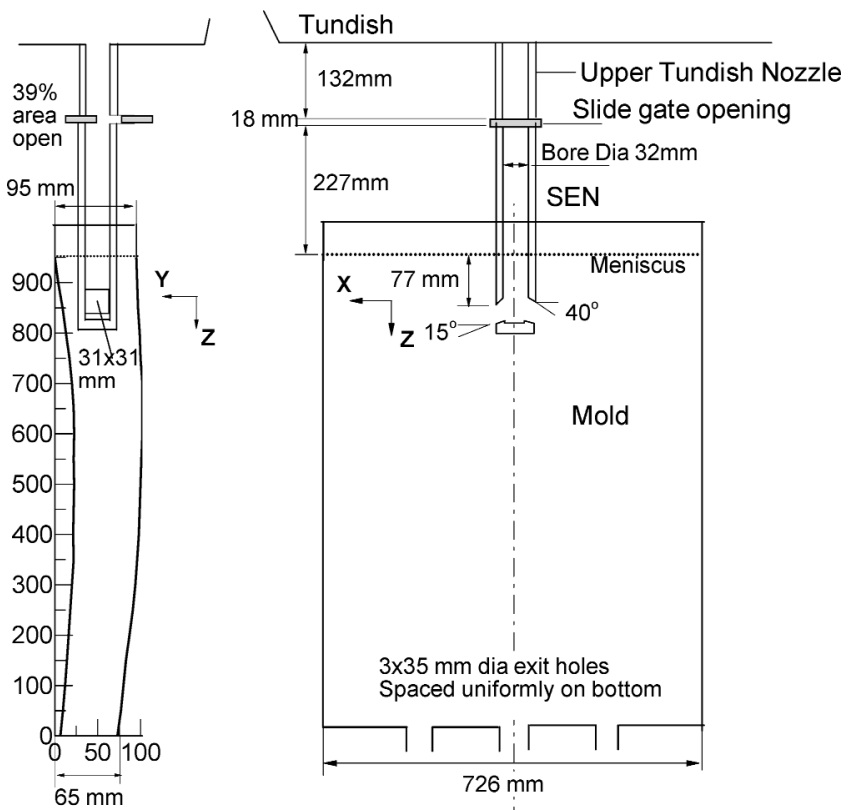

(a)

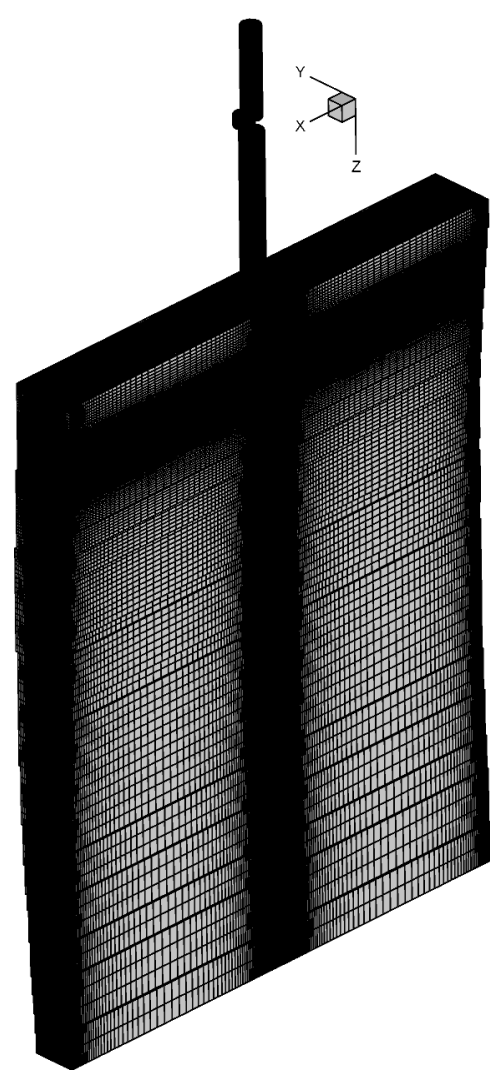

(b)

Fig. 1-Schematics of the 0.4-scale water model: $(a)$ dimensions and (b) the computational domain. model, has been extensively adopted in previous studies and has produced valuable insights about the flow in continuous casting nozzles ${ }^{[21-24]}$ and molds. ${ }^{[10,25-29]}$ However, this approach, limited by its nature, is not suited for studying the time evolution of unsteady flow structures triggered by flow instabilities. Plant observations suggest that flow transients under the nominally steady operating conditions are very important. ${ }^{[30]}$ The LES and DNS approaches are better for solving the timedependent flow of the continuous casting process, in which the Reynolds number is of the order of $10^{5}$. Due to the prohibitive computational cost of DNS at high Reynolds numbers, LES is a more feasible way for solving this complex flow problem. Recently, a few attempts have been made to apply it to the continuous casting process. ${ }^{[13,14,31]}$ The principal idea of LES is that during the simulation, the time evolution of the large-scale (energy-containing) eddies is resolved and the small energy-dissipative eddies are "filtered." The filtering of the small eddies generates a residual stress tensor $^{[20]}$ in the Navier-Stokes momentum transport equation, which is included using a subgrid scale (SGS) model. Although LES is less expensive than DNS, it still requires considerable computational effort. In this article, the transient flow structures in a 0.4-scale water model are investigated using LES computations and PIV measurements.

\section{WATER MODEL}

Figure 1(a) depicts the schematics and dimensions of a 0.4scale water model constructed from transparent plastic plates at the former LTV Steel Technology Center (Cleveland, $\mathrm{OH}){ }^{[9,13]}$ The flow rate in this water model is controlled by a

Table I. Dimensions and Operating Conditions of the 0.4-Scale Water Model

\begin{tabular}{lc}
\hline Dimensions/Conditions & Value \\
\hline Slide-gate orientation & $90 \mathrm{deg}$ \\
Slide-gate opening (area) & $39 \mathrm{pct}$ \\
SEN bore diameter & $32 \mathrm{~mm}$ \\
SEN submergence depth & $75 \mathrm{~mm}$ \\
Port height $\times$ width & $32 \times 31 \mathrm{~mm}$ \\
Port thickness & $11 \mathrm{~mm}$ \\
Port angle, lower edge & $15 \mathrm{deg}$ down \\
Port angle, upper edge & $40 \mathrm{deg}$ down \\
Bottom well recess depth & $4.8 \mathrm{~mm}$ \\
Water model height & $950 \mathrm{~mm}$ \\
Water model width & $735 \mathrm{~mm}$ \\
$\quad$ (corresponding full scale & $1829 \mathrm{~mm}(72 \mathrm{in})$. \\
caster width) & $95 \mathrm{~mm}($ top $)$ \\
Water model thickness & to $65 \mathrm{~mm}(\mathrm{bottom})$ \\
& $229 \mathrm{~mm}(9 \mathrm{in})$. \\
(corresponding full scale & $3 \mathrm{round} 35-\mathrm{mm}-$ \\
$\quad$ caster thickness) & diameter holes \\
Outlet at the bottom of the & $3.53 \times 10^{-4} \mathrm{~m}^{3} / \mathrm{s}$ \\
water model & $0.439 \mathrm{~m} / \mathrm{s}$ \\
Inlet volumetric flow rate & $10.2 \mathrm{~mm} / \mathrm{s}$ \\
through each port & $(0.611 \mathrm{~m} / \mathrm{min})$ \\
Mean velocity inside nozzle bore & $1000 \mathrm{~kg} / \mathrm{m}^{3}$ \\
Casting speed (top thickness) & $1.0 \times 10^{-6} \mathrm{~m}^{2} / \mathrm{s}$ \\
& $0 \mathrm{pct}$ \\
Water density & \\
Water kinematic viscosity & \\
Gas injection & \\
\hline
\end{tabular}


slide gate that moves in the mold thickness ( $y$ ) direction. The bifurcated submerged entry nozzle (SEN) shown in the figure has two downward-angled square nozzle ports, with top and bottom edges angled downward at 40 and $15 \mathrm{deg}$, respectively. No gas is injected. The Reynolds number at the nozzle port, based on its hydrodynamic diameter, is $\sim 12,000$. It is also shown in the figure that the mold thickness tapers from the top $(95 \mathrm{~mm})$ to the bottom $(65 \mathrm{~mm})$, so that the mold cavity represents only the liquid portion in the steel caster. Water flows into the mold cavity, recirculates, and finally exits from three $35-\mathrm{mm}$ outlet holes spaced $180 \mathrm{~mm}$ apart along the plastic bottom wall. A photograph of flow in this water model is given in Figure 19, visualized using die injection. Table I gives the details of the water model geometry and its operating conditions. Further details are available elsewhere. ${ }^{[23,24]}$

\section{COMPUTATIONAL MODEL}

Flow in the 0.4-scale water model is solved using LES. The computational domain is shown in Figure 1(b). It starts at the tundish exit, includes the upper tundish nozzle (UTN), the slide gate, the SEN, and the complete tapered mold cavity; it ends at the mold bottom. The domain is discretized using a Cartesian grid consisting of $\sim 1.5$ million finite volumes.

\section{A. Governing Equations}

In the context of LES, only the large-scale flow structures are resolved in the simulation. The dissipative effect of the small-scale eddies, which are smaller than the finite volume and therefore filtered during the simulation, is represented using an SGS model. The governing equations for the resolved flow field account for conservation of mass and momentum as $^{[20]}$

$$
\begin{gathered}
\frac{\partial v_{i}}{\partial x_{i}}=0 \\
\frac{D v_{i}}{D t}=-\frac{1}{\rho} \frac{\partial p}{\partial x_{i}}+\frac{\partial}{\partial x_{j}} \nu_{e f f}\left(\frac{\partial v_{i}}{\partial x_{j}}+\frac{\partial v_{j}}{\partial x_{i}}\right)
\end{gathered}
$$

where

$$
\nu_{\text {eff }}=\nu_{0}+\nu_{t}
$$

The symbols $p$ and $v_{i}$ in Eqs. [1] and [2] represent the pressure and filtered velocities. The subscripts $i$ and $j$ represent the three Cartesian directions and repeated subscripts imply summation. The residual stresses, which arise from the unresolved small eddies, are modeled using an eddy viscosity $\left(\nu_{t}\right)$. An important issue here is the selection of an appropriate SGS model for this complex industrial flow problem. In the past, a class of SGS kinetic energy (SGS k) models have been developed for simple problems such as flow in a channel. ${ }^{[32-36]}$ The SGS k model employed here requires solving the following additional transport equation, which includes advection, production, dissipation, and viscous diffusion. ${ }^{[33,36]}$

$$
\frac{\partial \mathrm{k}_{s g s}}{\partial t}+v_{i} \frac{\partial \mathrm{k}_{s g s}}{\partial x_{i}}=v_{t}|\widetilde{S}|^{2}-C_{\varepsilon} \frac{\mathrm{k}_{s g s}^{3 / 2}}{\Delta}+\frac{\partial}{\partial x_{i}}\left(v_{0}+2 v_{t} \frac{\partial \mathrm{k}_{s g s}}{\partial x_{i}}\right)
$$

where

$$
\begin{gathered}
\Delta=\left(\Delta_{x} \Delta_{y} \Delta_{z}\right)^{1 / 3} \\
\nu_{t}=C_{l} \Delta \mathrm{k}_{s g s}^{3 / 2}
\end{gathered}
$$

where $|\widetilde{S}|$ is the magnitude of the strain-rate tensor, defined as

$$
|\widetilde{S}|=\sqrt{2 \widetilde{S}_{i j} \widetilde{S}_{i j}}
$$

where

$$
\widetilde{S}_{i j}=\frac{1}{2}\left(\frac{\partial v_{i}}{\partial x_{j}}+\frac{\partial v_{j}}{\partial x_{i}}\right)
$$

The parameters $C_{\varepsilon}$ and $C_{l}$ can be treated as constants ${ }^{[33]}$ or evaluated dynamically during the simulation by assuming similarity between the subgrid stress tensor and the largescale Leonard stress tensor. ${ }^{[36]}$ This work adopts a static SGS k model with constant values 1.0 and 0.1 for $C_{\varepsilon}$ and $C_{l}$, respectively. ${ }^{[33]}$

\section{B. Boundary Conditions}

The flow enters the computational domain from the top opening of the UTN, which connects the tundish bottom with the nozzle. A uniform velocity of $1.15 \mathrm{~m} / \mathrm{s}$ is prescribed at the inlet opening based on the desired mass flow rate. The no-slip boundary condition is employed at the wall boundaries. The top surface of the water in the mold cavity is modeled as a free-slip plane ( $z$ velocity and $z$ gradient of all other variables set to zero). A constant pressure boundary condition is used at the three outlet ports in the bottom wall, where the gradients of all the other variables are set to zero.

\section{Solution Procedure}

The time-dependent three-dimensional filtered Navier-Stokes equations ${ }^{[1,2,4]}$ are discretized using the Harlow-Welch fractional step procedure. ${ }^{[37]}$ Second-order central differencing is used for the convection terms, and the Crank-Nicolson scheme $^{[38]}$ is used for the diffusion terms. The Adams-Bashforth scheme ${ }^{[39]}$ is used to discretize in time with second-order accuracy. The pressure Poisson equation is solved using an algebraic multigrid (AMG) solver. ${ }^{[40]}$

\section{Computational Details}

The computational domain depicted in Figure 1(b) is discretized using $\sim 1.5$ million Cartesian finite volumes. Smaller grid spacing $(\sim 0.8 \mathrm{~mm})$ is set at the nozzle outlet port and near the narrow face walls. The adequacy of this mesh refinement is demonstrated in separate investigations of the computational issues in LES modeling of continuous casting. ${ }^{[14,41]}$ The time step $(\Delta t)$ is set to 0.0003 seconds to keep the simulation stable $\left(\mathrm{CFL}=\Delta t \max \left(\frac{\bar{v}_{x}}{\Delta x}+\frac{\bar{v}_{y}}{\Delta y}+\frac{\bar{v}_{z}}{\Delta z}\right)<1:^{[42]}\right.$ here the CFL number was found to be $\sim 0.6$, so the results should be accurate). The computational time was 24 hours for 1 second of integration time on a Pentium IV 3.2 GHz PC (Linux 8.0, Redhat, Raleigh, NC). Time mean and variation values were calculated after the flow reached a statistically stationary 
state. ${ }^{[43]}$ Variations are characterized by their root-meansquare (rms) values, such as $\left(\overline{v^{\prime} v^{\prime}}\right)^{1 / 2}$, which is computed by $\left(\frac{1}{\left(t_{2}-t_{1}\right)} \sum_{t_{i}=t_{1}}^{t_{2}}\left(v\left(t_{i}\right)-\bar{v}\right)^{2} \Delta t\right)^{1 / 2}$, where $\left(t_{2}-t_{1}\right)$ is the time interval for the average and $\Delta t$ is the time step size. The mean and rms velocities were calculated for 51 seconds $(170,000$ time steps) and 20 seconds (70,000 time steps), respectively.

\section{PIV MEASUREMENTS}

The principle of PIV is to determine the flow velocities by measuring the displacement vector of illuminated particle images during a known time interval, as shown in Figure 2. In this work, aluminum powder with particle diameters of approximately $30 \mu \mathrm{m}$ was seeded into the fluid before the measurements. ${ }^{[13]}$ A Nd:YAG laser was used to illuminate the flow field. ${ }^{[13]}$ The CCD camera used in this work was a DANTEC-Double Image 700 (DANTEC Dynamics, Stovlunde, Denmark) with $768 \times$ 480 pixels. ${ }^{[13]}$ To generate enough particle images in each interrogation area to give an accurate average, an image resolution of $32 \times 32$ pixels per interrogation was used in this study. This produced a measured field of $32 \times 19$ vectors. In addition, to avoid problems arising from the crossover of particles near area edges moving between adjacent areas, the interrogation areas were made to overlap each other by 25 pct.

Because of our interest in the relatively large-scale flow structures in the water model, a large measurement area was selected at the expense of the relatively low overall resolution (compared to the computation). Owing to the limited number of camera pixels, the illuminated flow domain was divided into three regions, as shown in Figure 2: the upper region (0 to $0.25 \mathrm{~m}$ ) containing the jet and the upper two rolls, the middle region $(0.25$ to $0.65 \mathrm{~m})$, and the lower region $(0.65$ to $0.77 \mathrm{~m})$ containing the two lower rolls. Because the SEN blocks the laser, the flow in each half of the upper region was measured separately. During measurements, the time interval between two consecutive laser pulses was set at $1 \mathrm{~ms}$. The number of snapshots (pairs of pulses) collected and the time interval between them (which varies from 0.2 to $1 \mathrm{sec}$ ond) were determined depending on the time scales of the

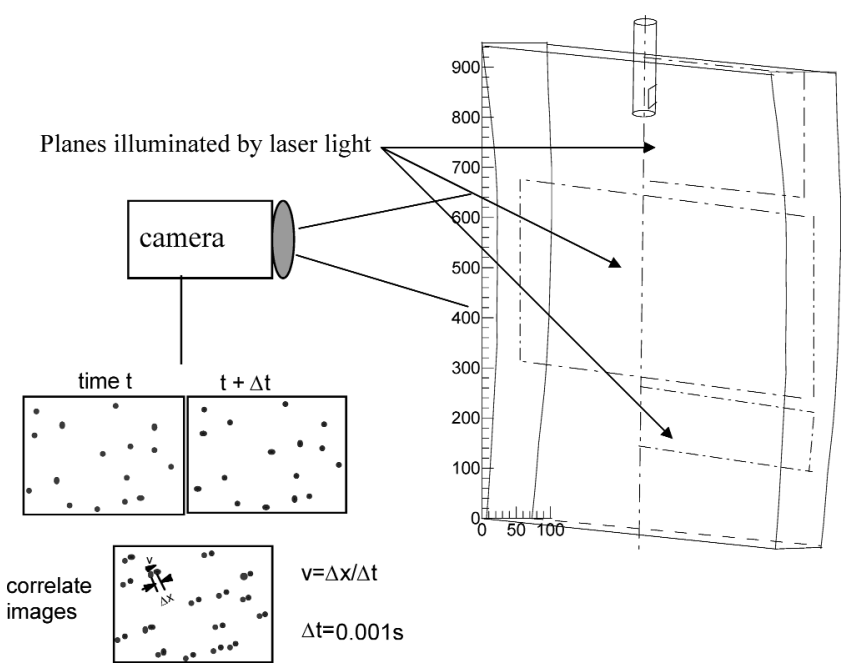

Fig. 2-Schematics showing the PIV measurement regions. flow in the respective regions. The collected data total 900 snapshots of one half of the mold spaced 0.2 seconds apart for the top portion, 2000 snapshots of both halves spaced 1 second apart, 400 snapshots of one half spaced 0.2 seconds apart for the middle region, and 200 snapshots of both halves spaced 0.2 seconds apart for the bottom region.

\section{FLOW IN THE SEN}

Flow in the nozzle is important because a detrimental flow pattern may lead to problems such as clogging, which both limits productivity and causes defects. ${ }^{[44]}$ In addition, the SEN ports direct the fluid into the mold cavity, which controls the jet angle, the flow pattern, and the corresponding steel quality issues. In this study, flow in the UTN and SEN could not be reliably measured using PIV, due to the curvature and partial opacity of the nozzle wall. Thus, this section presents the computed flow field in the nozzle region and compares it with measurements only at the port outlets.

Figure 3 gives an overall view of the computed velocities in the UTN and SEN at the centerline slice $(x=0)$. The plot on the left shows a representative instantaneous velocity field. The time-dependent velocities in the nozzle were averaged over 51 seconds and are shown in the right two close-up plots. In both the instantaneous and time-averaged

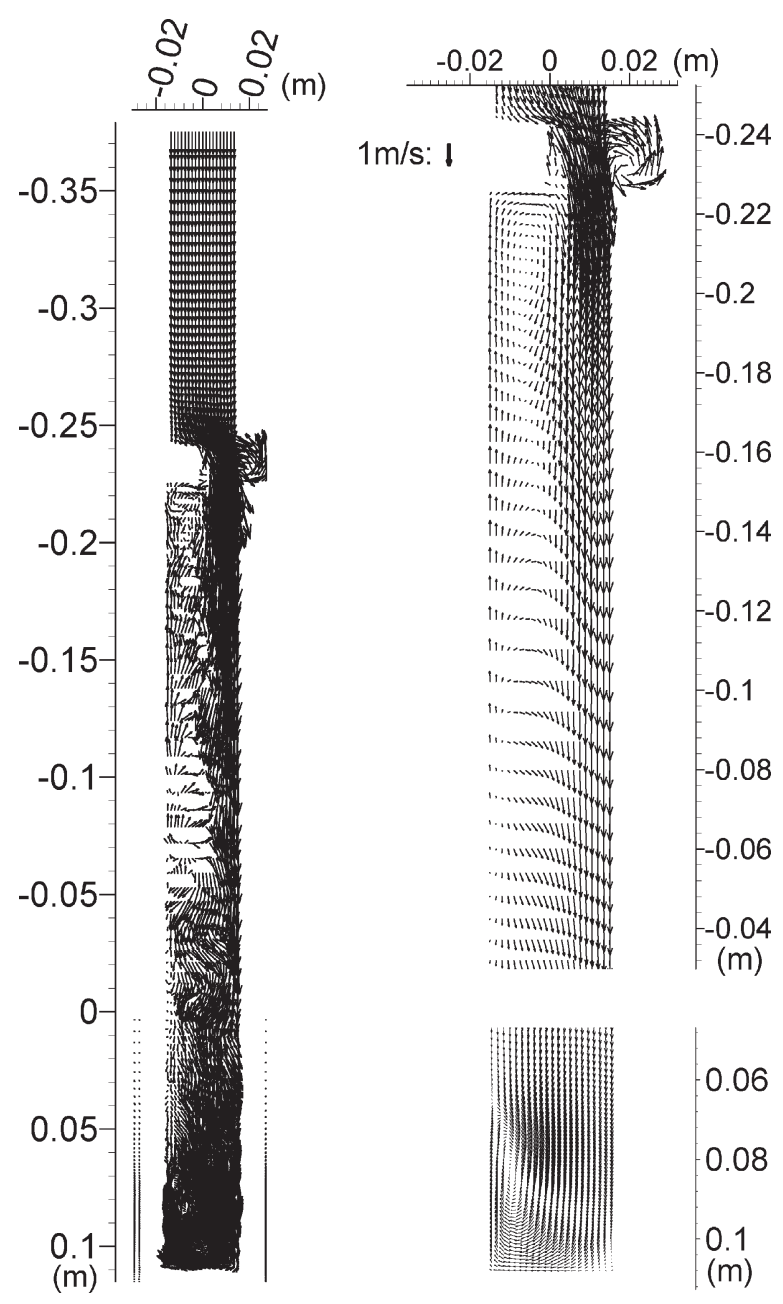

Fig. 3-Computed velocity field at the center plane $x=0$ of the SEN. 
plots, the narrowed flow passage at the slide gate induces large downward velocities $(\sim 3 \mathrm{~m} / \mathrm{s})$. These velocities exceed the mean velocity down the nozzle bore by 7 times and diminish gradually with distance down the nozzle. A recirculation flow is seen in the cavity of the slide gate. A large, elongated recirculation zone is also observed in the SEN beneath the slide gate and extends almost to the nozzle ports. This recirculation zone is complex, and actually exhibits multiple transient recirculation regions. These recirculation flows encourage the accumulation of impurity inclusions in the molten steel by increasing their residence time, and may cause problems such as clogging. The plot on the right bottom reveals a clockwise swirl in the $y-z$ plane near the SEN bottom. This swirl is clearly induced by the partial opening of the slide gate. The swirl is transported downstream with the flow to exit the nozzle ports, as shown in Figure 4, which depicts the time-averaged velocity vectors leaving the nozzle ports. In Figure 4(a), the cross-stream velocities in the outer plane of the nozzle outlet $(x=0.027 \mathrm{~m})$ are plotted for the view looking into the port. The single swirl persists here also. Figure 4(b) shows the velocity vectors at the centerline slice $y=0$, and indicates that most of the fluid exits the nozzle from the lower half of its ports. Reverse flow is

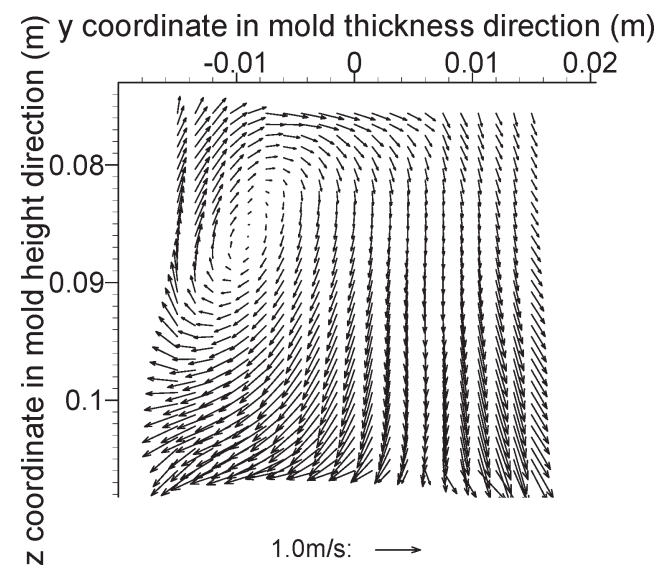

(a)

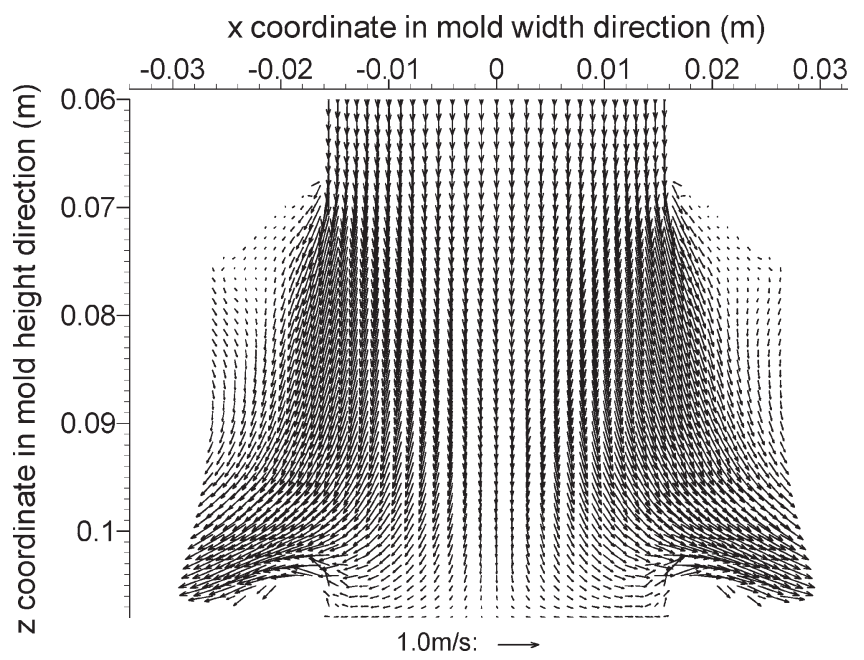

(b)

Fig. 4-Computed time-averaged velocity field exiting nozzle ports: (a) view into the port and (b) slice $y=0$. observed in the upper portion of the port. This result is consistent with previous work ${ }^{[23,45]}$ and is expected because the port-to-bore area ratio (2.47) greatly exceeds 1 . Comparing the velocity vectors in Figures 4(a) and (b), the cross-stream velocity components are seen to be comparable in magnitude to the streamwise components.

Figure 5 shows the time-averaged flow speed $\left({\overline{v_{x}}}^{2}+{\overline{v_{z}}}^{2}\right)^{1 / 2}$ along the nozzle port vertical centerline. The PIV data shown here were collected in the mold cavity close to the nozzle ports. ${ }^{[46]}$ They are the average of 50 PIV snapshots spaced 0.2 seconds apart. ${ }^{[46]}$ The computed speed is seen to have a similar distribution to that obtained from PIV. In both LES and PIV, the "peak" speed occurs $3 \mathrm{~mm}$ above the lower edge of the nozzle port. The computed speeds are consistently larger than the measured values in the lower portion of the port, however. In previous work, misalignment of the laser plane was suspected as the reason for this discrepancy. ${ }^{[23]}$ Another suspected reason is that the relatively large off-plane velocity component $\left(\bar{v}_{y}, 0.2\right.$ to $\left.0.3 \mathrm{~m} / \mathrm{s}\right)$ in the lower portion of the port makes the tracer particles in the water model move 0.2 to $0.3 \mathrm{~mm}$ during the $1-\mathrm{ms}$ time interval between two consecutive laser pulses. The typical thickness of the laser sheet is $1 \mathrm{~mm}$. Particles moving in and out of the illuminated plane could confuse the measurement.

Figure 6 presents a sequence of the computed instantaneous snapshots of the flow at the nozzle outlet port to reveal its evolution. In Figure 6(a), a strong clockwise swirl is seen to occupy almost the whole port area. After 4 seconds, the size of this swirl reduces to $2 / 3$ of the port area, with cross-stream velocities in the other $1 / 3$ portion dropping close to zero (Figure 6(b)). It then breaks into many distinct small vortices 1 second later, as shown in Figure 6(c), and further evolves into a nearly symmetric double swirl another 4 seconds later (Figure $6(d)$ ). The flow at the nozzle port is seen to fluctuate between these four representative patterns. This same behavior was observed in visual observations of the water model. However, the strong cross-stream flow is not seen when a stopper rod is used instead of a slide gate. ${ }^{[14]}$

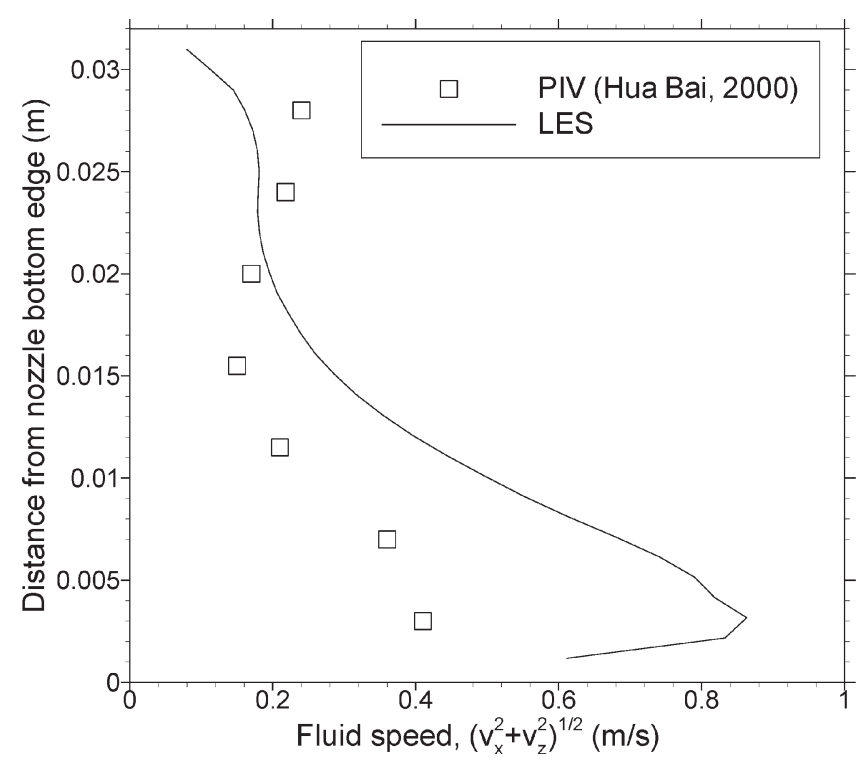

Fig. 5-Time-averaged fluid speed $\left({\overline{v_{x}}}^{2}+{\overline{v_{z}}}^{2}\right)^{1 / 2}$ along the vertical centerline of the SEN nozzle ports. 


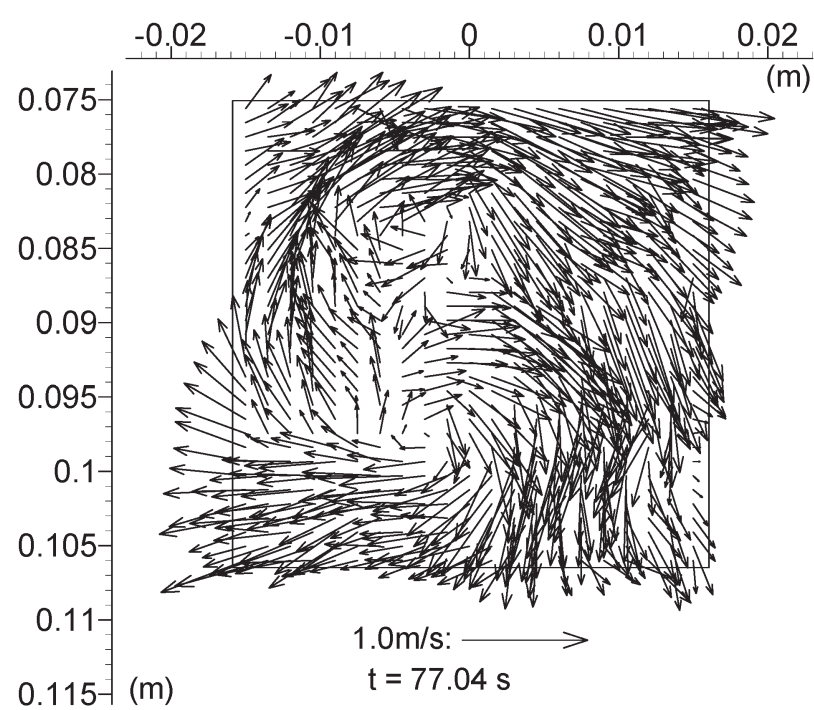

(a)

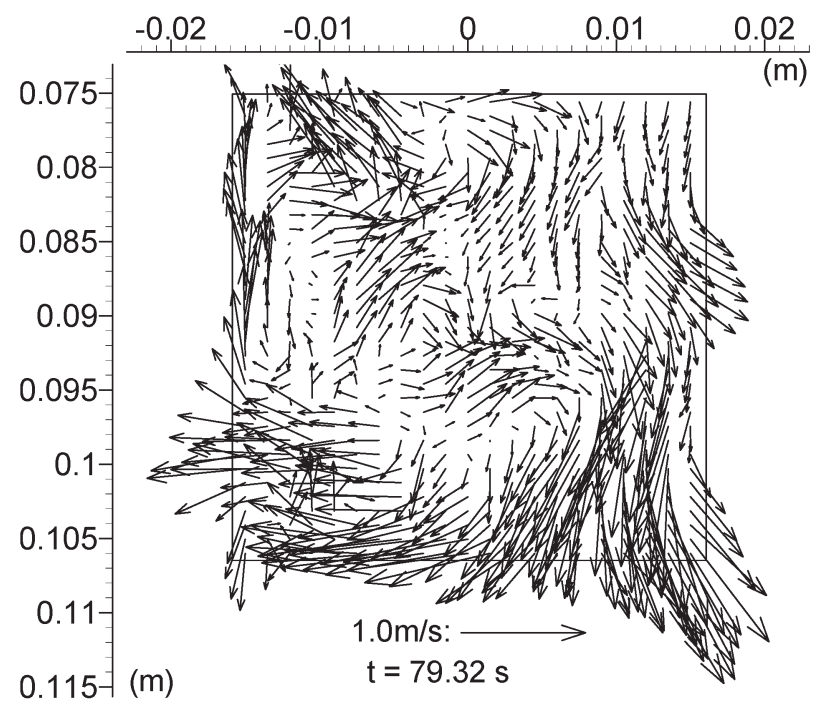

(c)

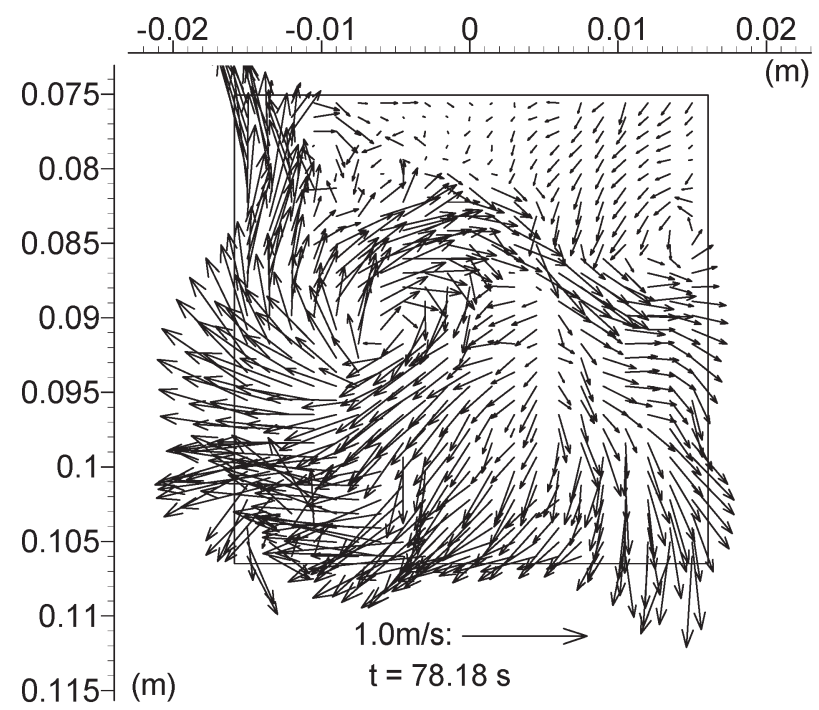

(b)

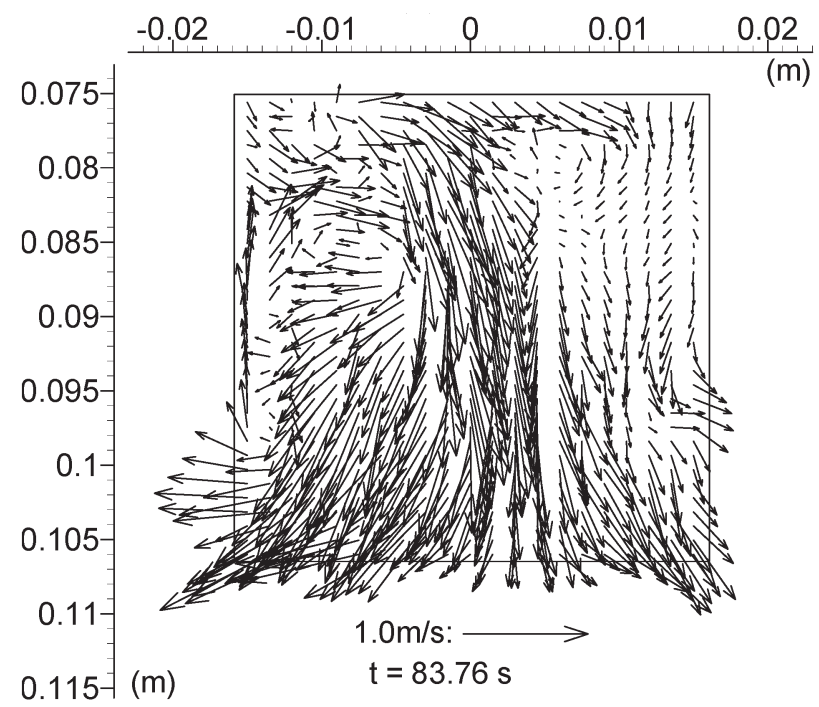

(d)

Fig. 6- (a) through $(d)$ Representative instantaneous cross-stream flow patterns exiting the nozzle port obtained from LES, view into the port.

\section{FLOW IN THE MOLD CAVITY}

The jet exiting the SEN feeds into the mold cavity, where it controls the flow pattern and corresponding phenomena, which affect quality problems. If insufficient superheat is transported with the jet to the top surface, then the meniscus may freeze to form subsurface hooks, which may entrap inclusions and cause slivers. The contour of the top surface beneath the flowing liquid affects flux infiltration into the gap, which controls lubrication and surface cracks. Excessive flow fluctuations can cause fluctuations in the top surface level, disrupting meniscus solidification and causing surface defects. Excessive velocity across the top surface can shear fingers of molten mold flux into the steel, leading to inclusion defects when the particles eventually become entrapped. ${ }^{[47]}$ The mold region is the last step during which impurity particles could be removed without being entrapped in the solid steel slabs. Knowledge of the turbulent flow in the mold region is critical for understanding all of these phenomena. This section presents the details of the turbulent flow in the mold cavity of the water model.

\section{A. Time-Averaged Flow Structures}

After the computed flow reached a statistically stationary state, ${ }^{[43]}$ the means of all variables were collected by averaging the instantaneous flow fields obtained at every time step. Figure 7 presents the simulated flow field at the center plane $y=0$ in the mold cavity averaged over 51 seconds. For clarity, velocity vectors are only shown at about every third grid point in each direction. The usual double-roll flow pattern ${ }^{[10,25]}$ is reproduced in each half of the mold. The two jets emerging from the nozzle ports spread and bend slightly upward as they traverse the mold region. The two lower rolls are slightly asymmetric, even in this timeaveraged plot. This indicates that flow transients exist with periods longer than the 51-second average time. 
Figure 8 gives a closer view of the upper roll. The PIV plot shown on the left is a 60 -second average of 300 instantaneous measurements. The right half shows some of the computed velocities plotted with a resolution comparable to that of the PIV. A jet angle of approximately $29 \mathrm{deg}$ is implied by the LES results, which is consistent with the flow visualization. ${ }^{[13]}$ A larger jet angle of 34 to $38 \mathrm{deg}$ is seen in the PIV vectors. This may be due to the manually adjusted laser sheet being off the center plane $(y=0)$. In both LES and PIV, the jet diffuses as it moves forward and becomes nearly flat $0.2 \mathrm{~m}$ away from the center. The eyes of the upper rolls are seen to be nearly $0.2 \mathrm{~m}$ away from the SEN center and $0.1 \mathrm{~m}$ below the top surface. The main difference

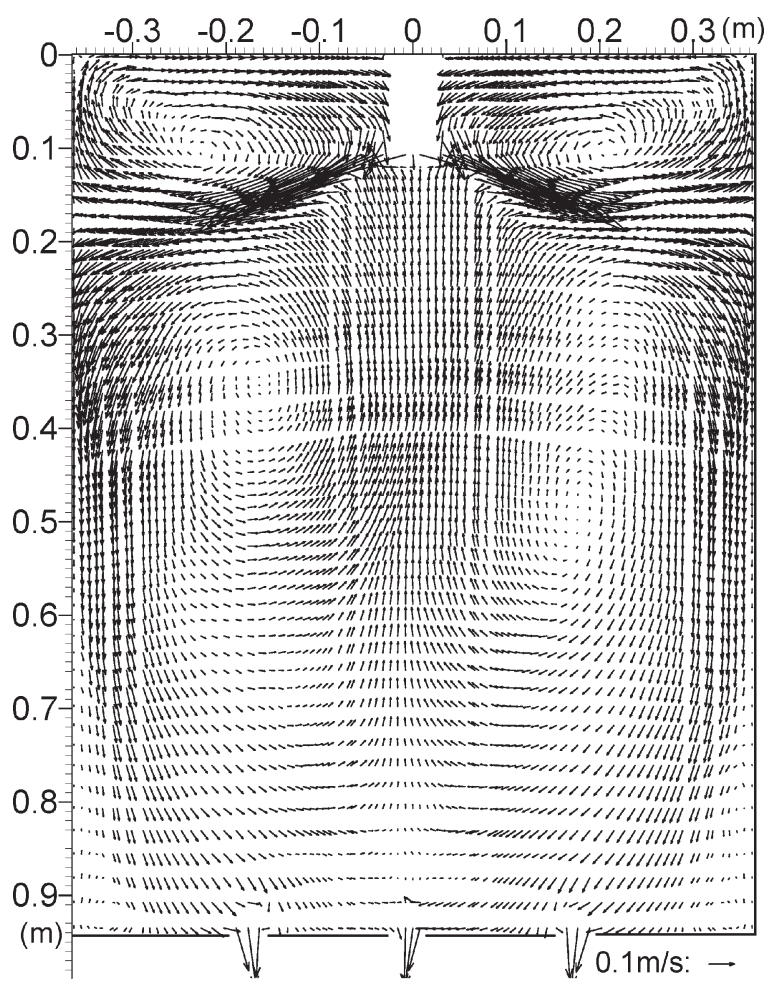

Fig. 7-Time-averaged velocity vector plot in the mold region obtained from LES. between the computed and measured velocities in the upper region is that the computed velocities are consistently higher than the measured values in the low-velocity regions. Perhaps this is because the PIV system is tuned to accurately measure velocities over a specific range (e.g., by adjusting the pulse interval), which might decrease accuracy in regions where the velocities are either much higher or much lower.

The time-averaged flow in the lower region is given in Figures 9(a) and (b). Both plots are for the center plane $y=0$. The LES data clearly show that the lower roll in the left half is smaller and about $0.1 \mathrm{~m}$ higher than the right one. This

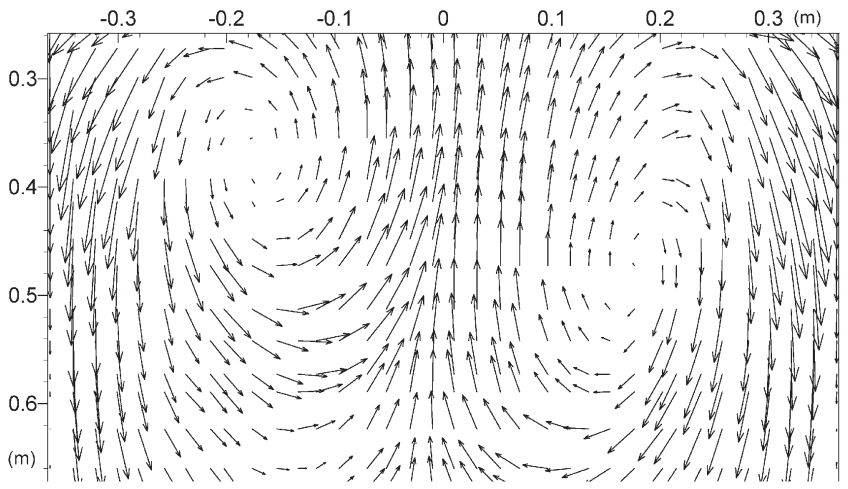

(a)

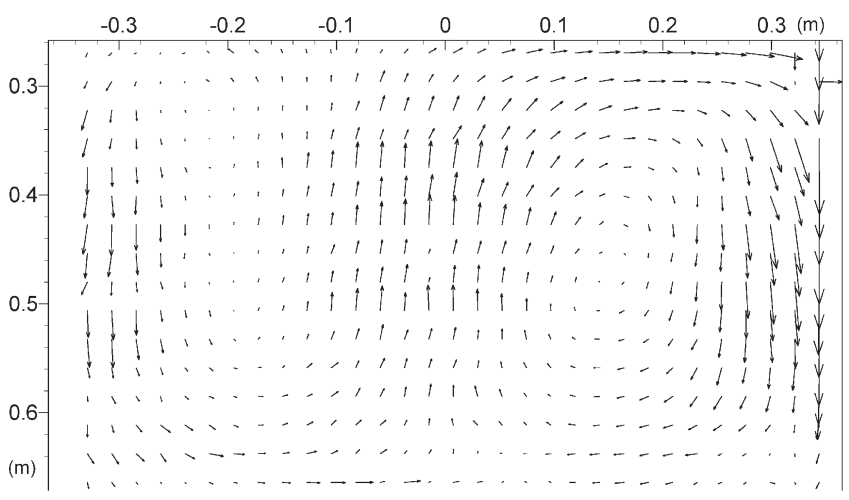

(b)

Fig. 9-Time-averaged velocity vectors in the lower roll region, obtained from (a) LES and (b) PIV measurements.

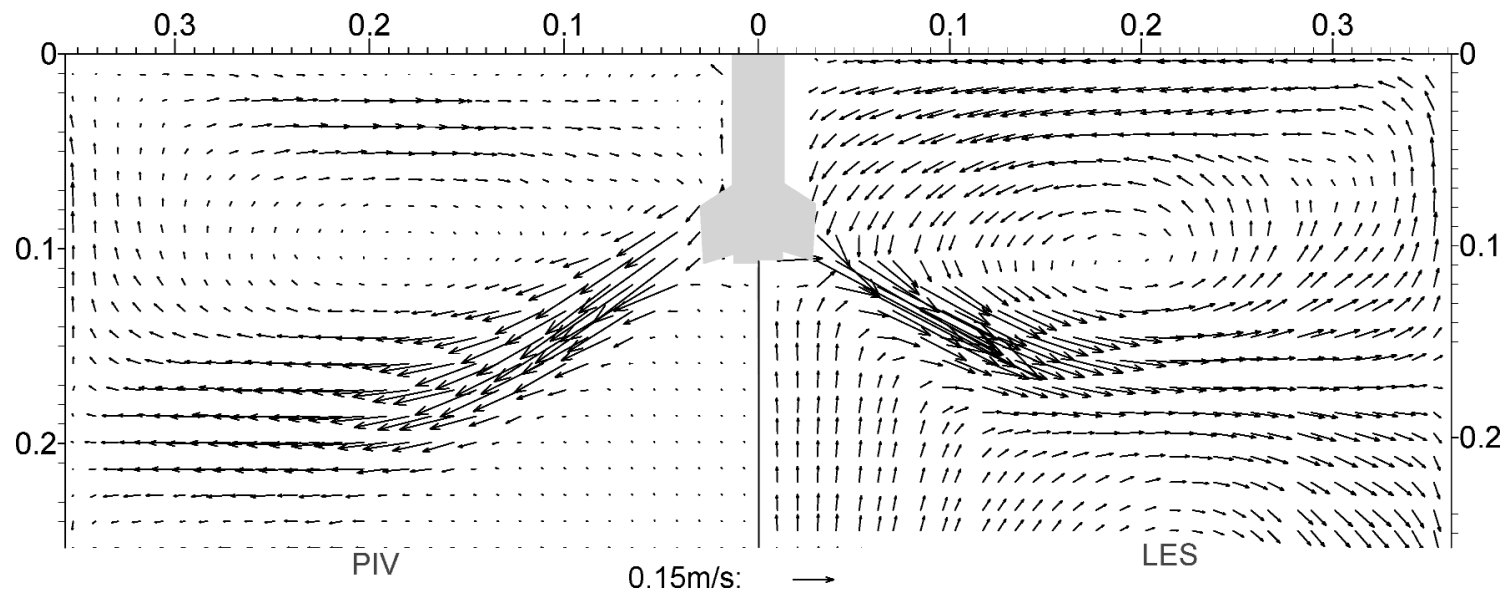

Fig. 8-Time-averaged velocity vectors in the upper roll sliced at $y=0$, obtained from PIV measurements and LES. 
confirms that a flow asymmetry exists in the lower roll region that persists longer than 51 seconds (the averaging time). In this region, ten sets of PIV measurements were conducted. Each set of measurements consists of 200 snapshots taken over 200 seconds. Figure 9(b) presents the velocity field averaged from all of the measurements. For all ten averages, the lower roll in the right half is larger and slightly lower than the left one. This proves that the asymmetry of the flow is persistent over long times, exceeding several minutes. It was also observed that for all the ten sets of PIV data, the downward velocities close to the right narrow face are always greater than those down the left side. It is not known whether this is due to the flow asymmetry or errors in the experiments (e.g., laser light diminishing as it traverses the flow field). This long-term flow asymmetry in the lower roll has been observed in previous work and may explain why inclusion defects may alternately concentrate on different sides of the steel slabs. ${ }^{[48]}$

\section{B. Velocities along Jets}

Figure 10 compares the computed speed $\left({\overline{v_{x}}}^{2}+{\overline{v_{z}}}^{2}\right)^{1 / 2}$ with PIV measured values along the jet centerline. The solid line denotes the speed obtained from the LES and averaged for 51 seconds. It shows that the jet exits the nozzle port at a speed $\sim 0.7 \mathrm{~m} / \mathrm{s}$ and slows down as it advects forward. It is seen that the 51-second average almost suppresses the differences between the left and right jets. Except in the region close to the nozzle port, a reasonable agreement between the computation and measurements is observed.

\section{Velocities on the Top Surface}

In a steel caster, the flow conditions at the interface between the molten steel and the liquid flux on the top surface are crucial for steel quality. Therefore, accurately predicting velocities there is important for a computational model. Figure 11 shows the time-averaged $x$ velocity component $\left(\overline{v_{x}}\right)$ toward the SEN along the top surface center line. Due to a lack of measurements at the current casting speed, two sets of averaged

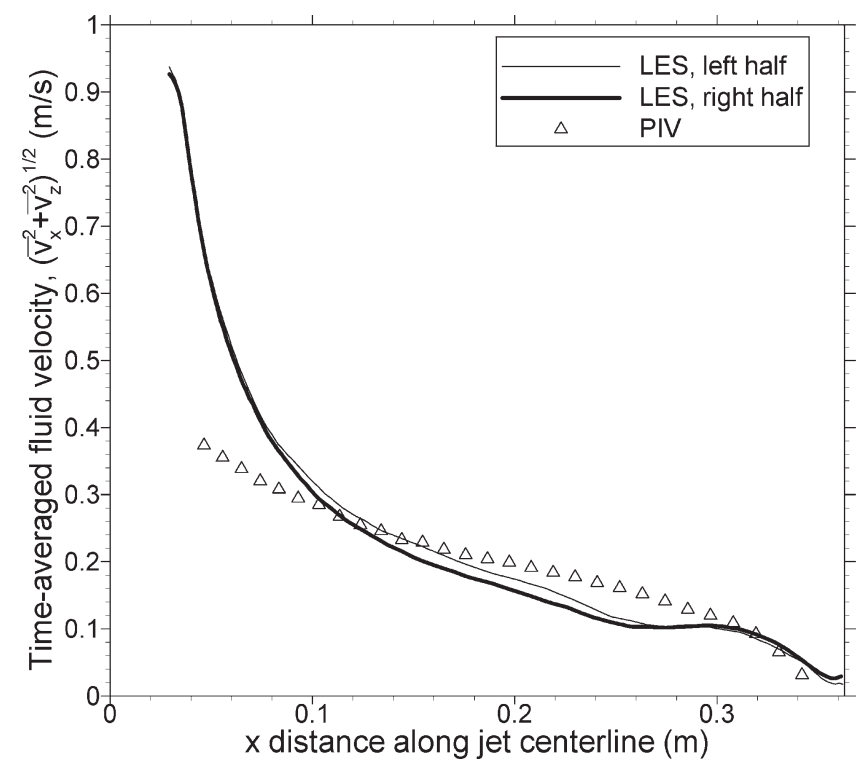

Fig. 10-Time-averaged fluid speed $\left(\bar{u}^{2}+\bar{w}^{2}\right)^{1 / 2}$ along jet centerline, obtained from LES (SGS-k model) and PIV measurements. data from other PIV (provided by Assar) ${ }^{[49]}$ are used to compare with the LES predictions. Each one of these is the average of a group of measurements conducted on the same water model at a constant casting speed slightly higher $(0.791 \mathrm{~m} / \mathrm{min})$ or lower $(0.554 \mathrm{~m} / \mathrm{min})$ than that in this work. It can be seen that this velocity component increases away from the SEN, reaches a maximum midway between the SEN and the narrow face, and decreases as it approaches the narrow face. The maximum of $\sim 0.15 \mathrm{~m} / \mathrm{s}$ is about $1 / 3$ of the mean velocity in the nozzle bore and $1 / 5$ of the maximum velocity of the jet exiting the nozzle. The comparison suggests that the computation agrees reasonably well with the PIV measurements.

The computed rms value of this velocity component is plotted in Figure 12. No PIV data are available for the rms on the top surface. The figure suggests that the rms of the $x$ velocity component $\left(\left(\overline{v_{x}{ }^{\prime} v_{x}{ }^{\prime}}\right)^{1 / 2}\right)$ decreases slightly from the SEN to the narrow face. The results also suggest that the rms of the velocity can be as high as 80 pct of the mean velocity, indicating very large turbulent velocity fluctuations.

Figure 13 compares the time variation of the horizontal velocity toward the SEN near the top surface for the simulation

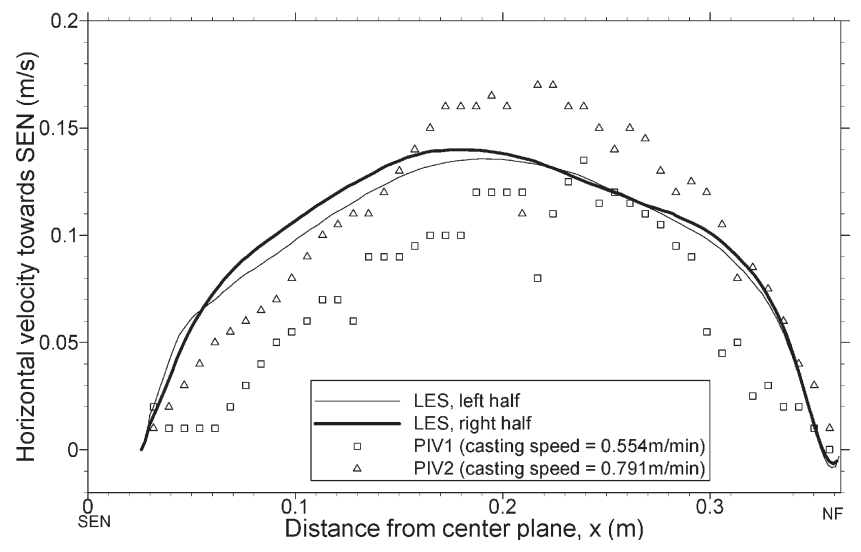

Fig. 11-Time-averaged horizontal velocity toward SEN along the top surface centerline.

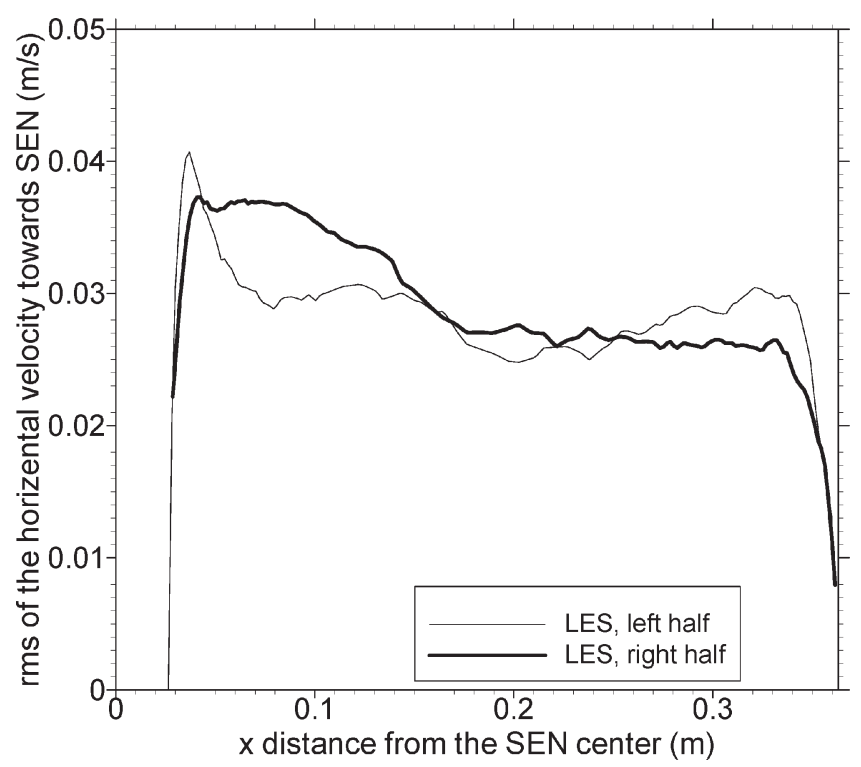

Fig. 12-The rms of the $u$-velocity component along the top surface centerline. 


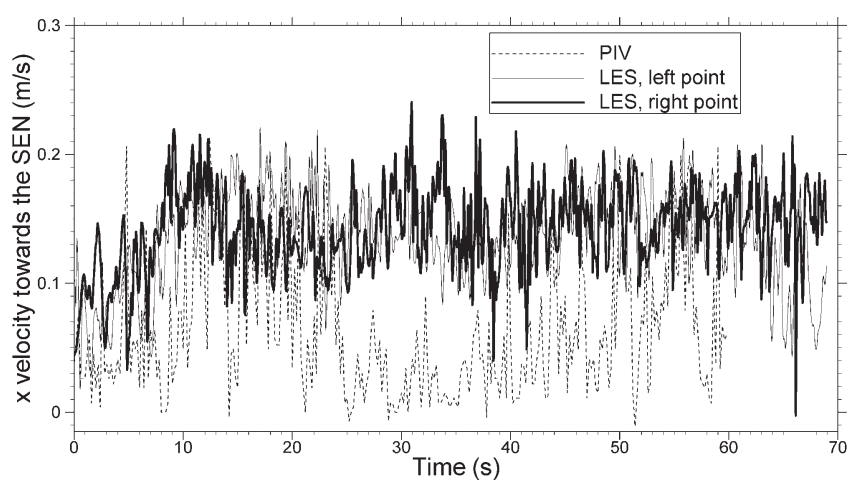

Fig. 13-Time history of the horizontal velocity toward SEN (20 mm below the top surface, midway between the SEN and narrow faces).

and the measurement. The data are taken at a point $20 \mathrm{~mm}$ below the top surface, midway between the SEN center and the narrow face. The mean PIV signal is lower than expected from the measurements in Figure 11, which shows variations between the PIV measurements taken at different times. The velocity fluctuations are seen to be large, with a magnitude comparable to the local mean velocities. Both the computation and measurement reveal a large fluctuating component of the velocity with approximately the same high frequency (e.g., the velocity drops from $\sim 0.21 \mathrm{~m} / \mathrm{s}$ toward the SEN to a velocity in the opposite direction within 0.7 seconds). This velocity variation is important, because the liquid level fluctuations accompanying it are a major cause of defects in the process. The computed signal reproduced most of the features seen in the measurements. The signal also reveals a lower frequency fluctuation with a period of about 45 seconds. A spectral analysis of the surface pressure signal near the narrow face on the top surface reveals predominant oscillations with periods of $\sim 7$ and 11 to 25 seconds, which are superimposed with a wide range of higher-frequency, lower-amplitude oscillations. Knowing that model surface pressure is proportional to level, ${ }^{[14]}$ this result compares with water model measurements of surface level fluctuations by Lahri ${ }^{[50]}$ that appear to have a period of $\sim 0.4$ seconds and by Honeyands and Herbertson $^{[51]}$ of $\sim 12$ seconds.

\section{Velocities in the Lower Roll Region}

Figure 14 shows the downward velocity profile across the width of the mold centerline, in the lower roll zone $(0.4 \mathrm{~m}$ below the top surface). As stated earlier, ten sets of 200-second 200-snapshot PIV measurements were conducted in both halves of the mold. The average of all sets is shown as open symbols. The error bars denote the range of the averages of all ten sets of measurements. The solid symbols correspond to a data set with large upward velocities near the center. In all data sets, the largest downward velocity occurs near the narrow face $(x=0.363)$. The computation is seen to overpredict the upward velocity measured right below the SEN. This may partially be due to the shorter averaging time $(51 \mathrm{sec}-$ onds) in LES compared to PIV, as the PIV results indicate significant variations even among the ten sets of 200-second time averages. This inference is further supported by the rms of the same velocity component along the same line shown in Figure 15. The open symbols and error bars again represent the rms velocity averaged for the ten sets of measure-

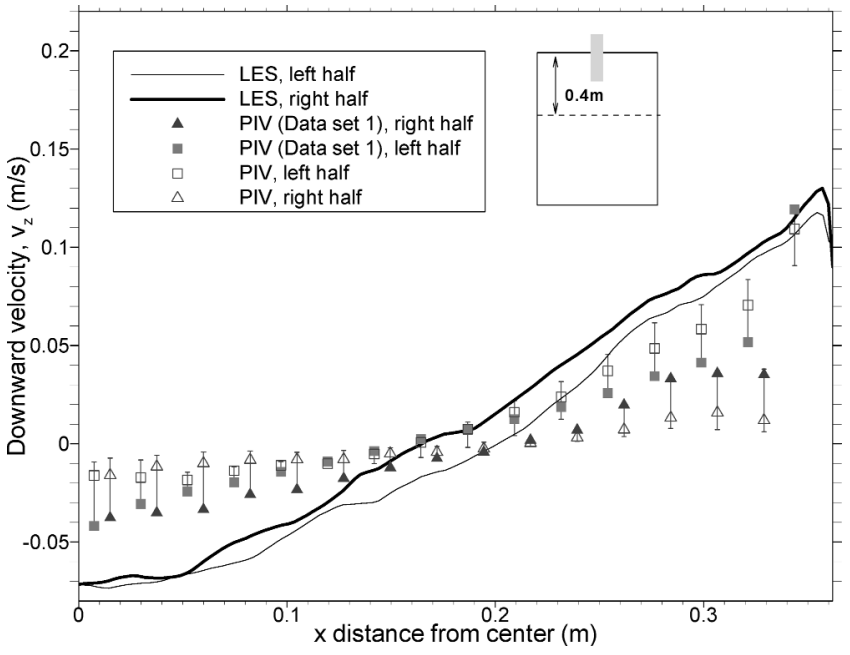

Fig. 14-Time-averaged downward velocity component across the width (along the horizontal line $0.4 \mathrm{~m}$ below the top surface, midway between wide faces).

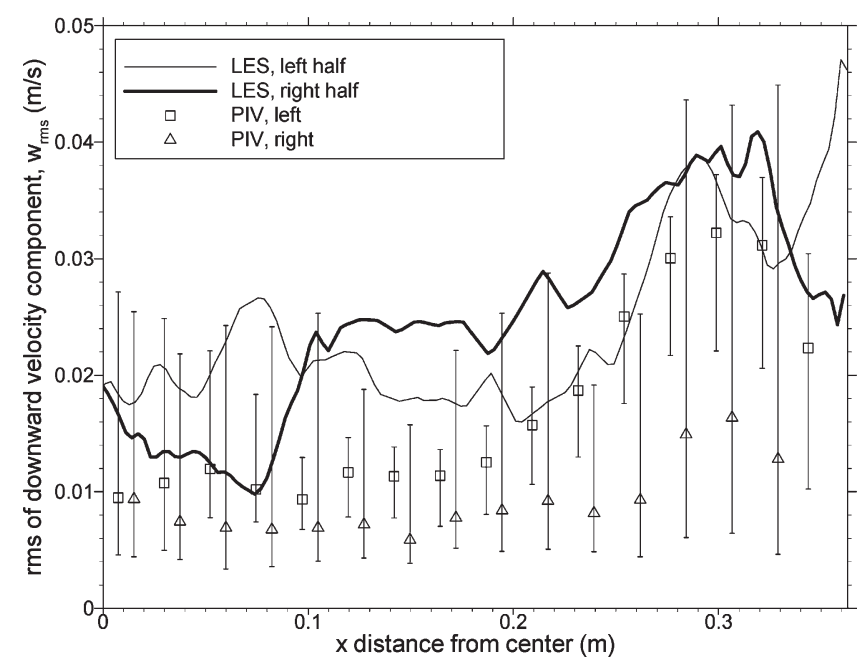

Fig. 15-The rms of the downward velocity component along the line in Fig. 7.

ments and the range. The results indicate large fluctuations of this vertical velocity in this region (e.g., near the center, the rms value is of the same magnitude as the time-averaged velocity). Both the time averages and rms are seen to change significantly across these 200 -second measurements, indicating that some of the flow structures evolve with periods much longer than 200 seconds. Accurate statistics in the lower roll, therefore, require long-term sampling. This agrees with measurements of the flow-pattern oscillation period of $\sim 40 \mathrm{sec}-$ onds (a 2- to 75-second range) conducted on a very deep water model. ${ }^{[52]}$

Figure 16 presents the downward velocity along two lines across the mold thickness, in the center-plane midway between the narrow faces $(x=0)$ in the lower roll. These results show a nearly flat profile of this velocity in the interior region along the thickness direction. This suggests that a slight misalignment of the laser sheet off the center plane should not introduce significant errors in the lower roll region. 


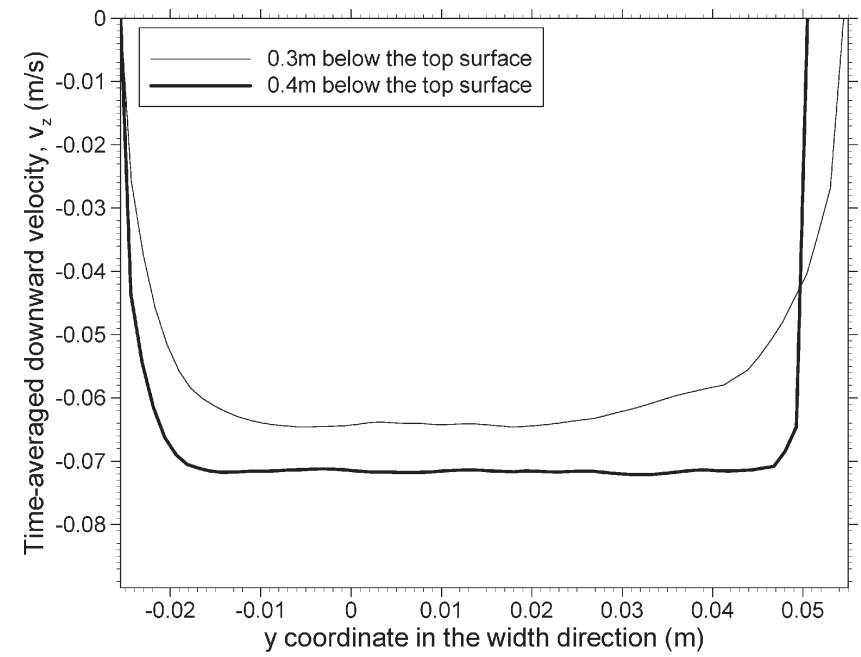

Fig. 16-Spatial variation of the downward velocity across the thickness direction (beneath SEN).

\section{E. Instantaneous Flow Structures}

The instantaneous flow pattern can be very different from the time-averaged one. The time-dependent flow structures in the mold cavity are presented in this subsection. Figure 17(a) gives an instantaneous velocity vector plot of the flow field in the center plane $(y=0)$ measured with PIV. It is a composite of the top, middle, and bottom regions shown in Figure 2 for each half. Each of the six frames was measured at a different instant in time. Figure 17(b) shows a corresponding typical instantaneous velocity field obtained from LES. The flow consists of a range of scales, as seen by the velocity variations within the flow field. The jets in both halves consist of alternate bands of vectors with angles substantially lower and higher than the jet angle at the nozzle port. The velocities near the top surface and the upper roll structure are observed to be significantly different between individual time instants and between the two halves. In both halves, the flow from the downward wall jet can be seen to entrain the fluid from a region below the SEN, although at different heights. Thus the shape and size of the two lower rolls appear significantly different for both PIV and LES.

Figure 18 gives a closer view of flow structures in the upper region obtained by LES and PIV. The upper plot shows a computed instantaneous velocity field at the center plane $y=0$. The lower velocity vector plot is a composite of two instantaneous PIV snapshots, divided by a solid line and obtained from measurements of the same flow field. A "stairstep" type of jet is observed in the left vector plot for both the simulation and measurement. This flow pattern is believed to result from the swirl in the jet (Figure 6): the swirling jet moves up and down and in and out of the center plane as it approaches the narrow face, causing a stair-step appearance in the center plane. The flow displayed in the right snapshot shows a shallower jet. The jet bends upward after traveling $\sim 0.25 \mathrm{~m}$ in the $x$ direction and splits into two vortices. In the actual steel casting process, this upward-bending jet may cause excessive surface level fluctuation, resulting in surface defects, while the deeper jet shown in the left plot may carry more inclusions into the lower roll region, leading to inclusion defects. These are the two representative instantaneous

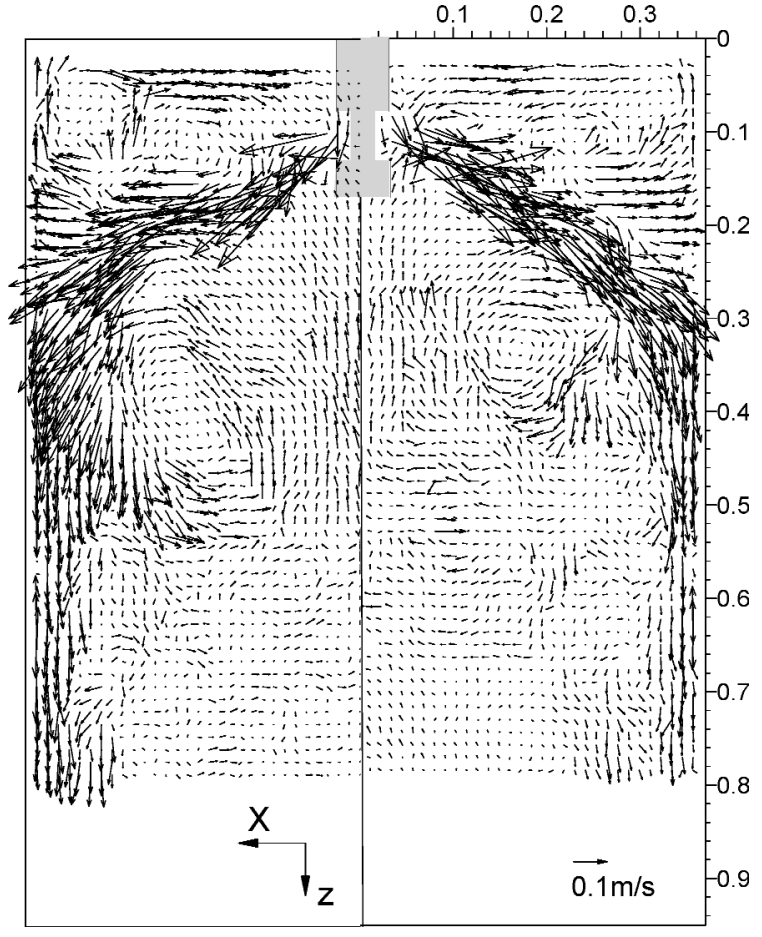

(a)

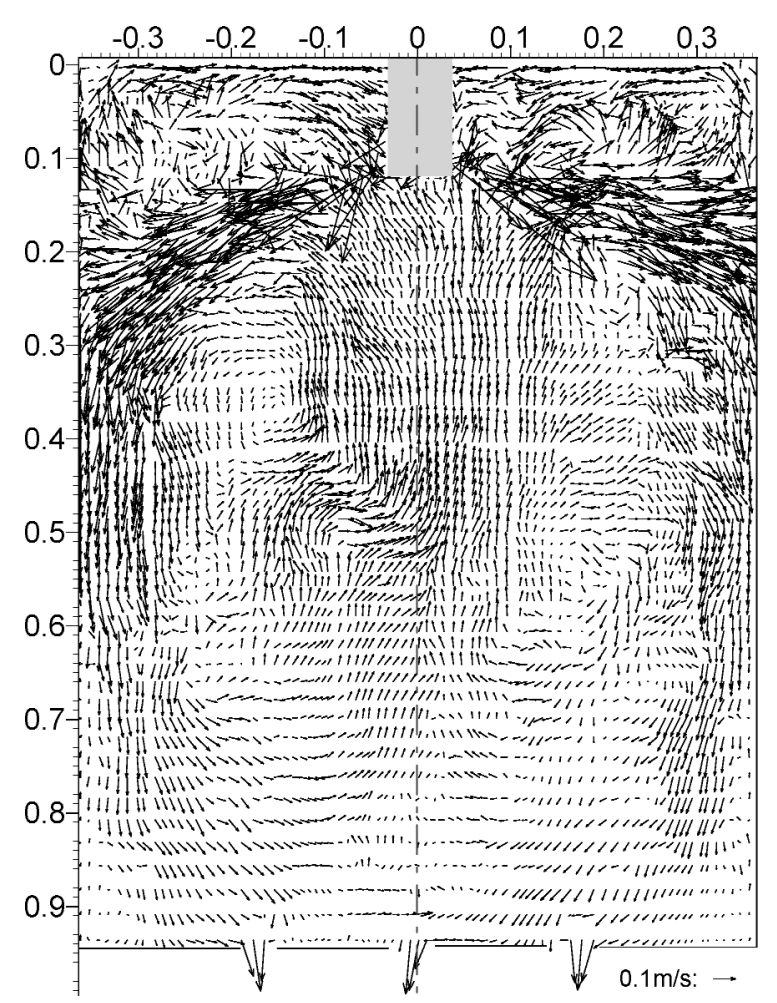

(b)

Fig. 17-An instantaneous snapshot showing the velocity field in the water model, obtained from $(a)$ PIV measurements and $(b)$ LES.

flow patterns in the upper region. Flow in this region is seen to switch randomly between the two patterns in both LES and PIV. An analysis of many frames reveals that the staircase pattern oscillates with a time scale of $\sim 0.5$ to 


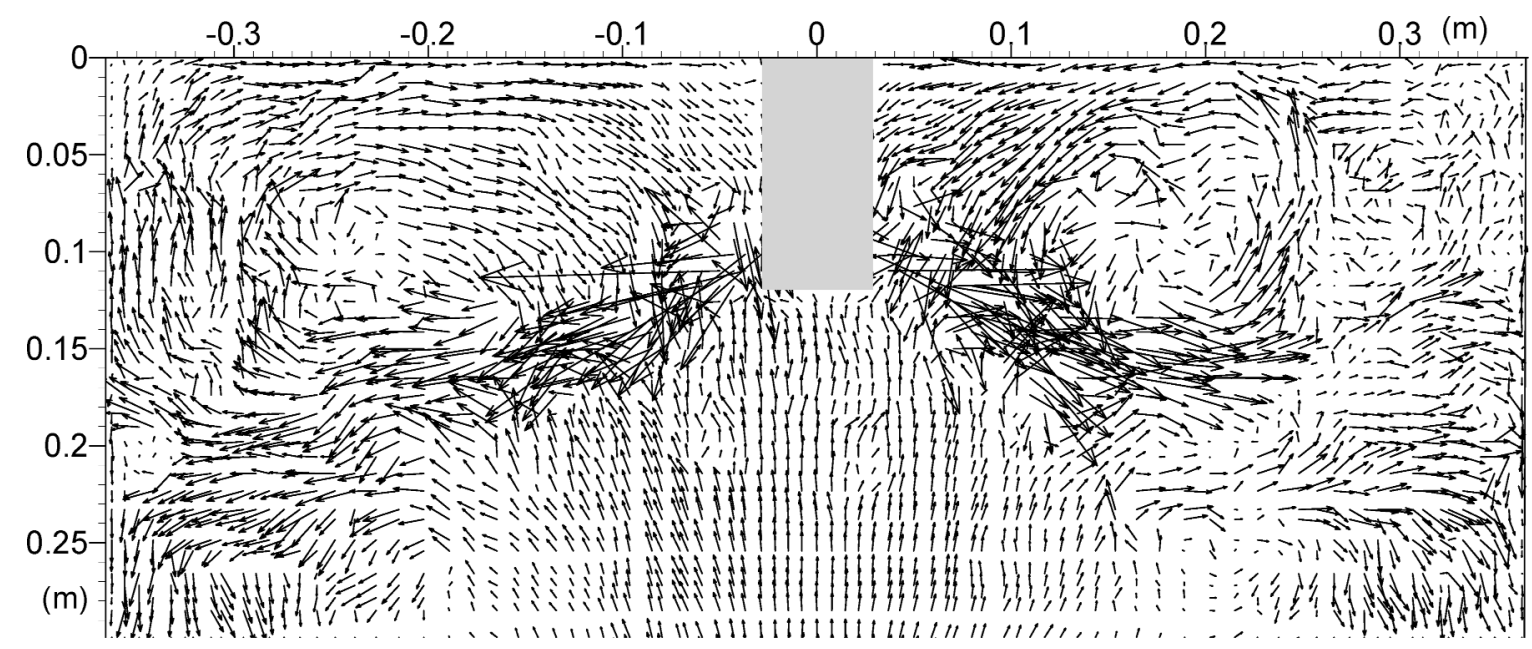

$0.5 \mathrm{~m} / \mathrm{s}$ :

(a)

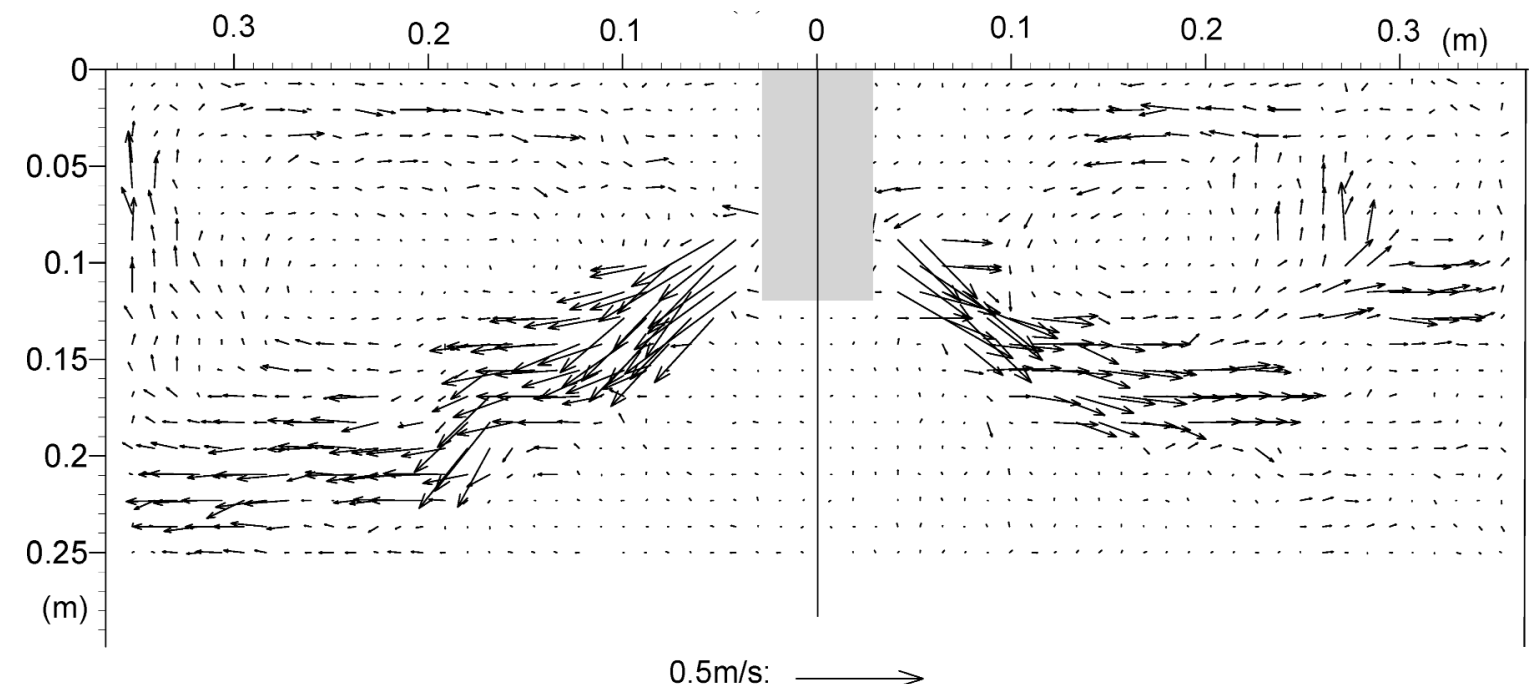

(b)

Fig. 18-Instantaneous velocity vector plots in the upper region obtained from (a) LES and (b) PIV measurements.

1.5 seconds. This is consistent with a spectral analysis of the velocity signal at this location, which shows strong frequency peaks at 0.6 and $0.9 \mathrm{~Hz}$, and many other smaller peaks at different frequencies.

The LES results also suggest that the instantaneous flow in the two halves of the mold can be very asymmetric. The asymmetry does not appear to last long in the upper mold because a 51-second average is seen to eliminate this asymmetry (Figures 7,10 , and 11). The instantaneous asymmetric flow in the upper roll is also evidenced by the dye-injection photograph in Figure 19. This picture suggests a flow pattern similar to that shown in Figure 18(a).

Two sequences of flow structures, obtained from LES and PIV, respectively, are compared in Figure 20, showing the evolution of the flow in the lower region. In the first plot (Figure 20(a)), a vortex can be seen in the left half approximately $0.35 \mathrm{~m}$ below the top surface and $0.15 \mathrm{~m}$ from the center. This vortex is seen in the next two plots to be transported downstream by the flow. In both LES and PIV, the vortex is transported about $0.15 \mathrm{~m}$ down in the 15 -second interval. The computed

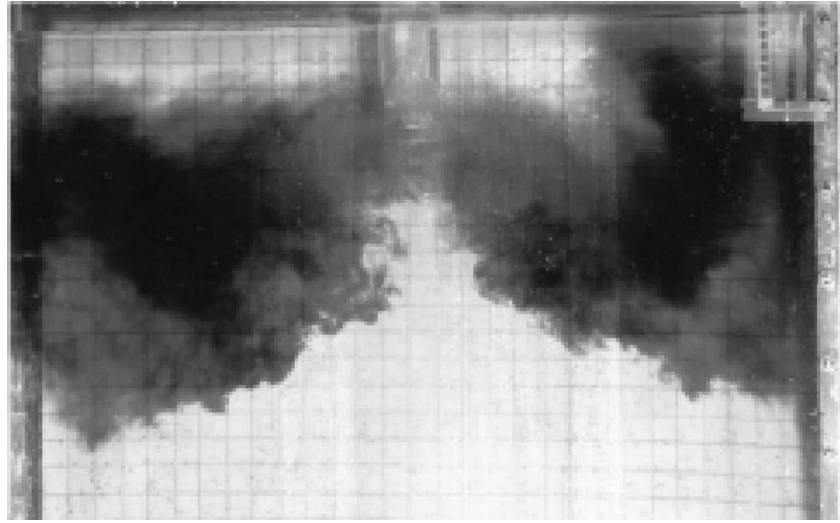

Fig. 19-Snapshot of dye injection in the water model, showing asymmetry between the two upper rolls.

instantaneous flow also shows that the sizes of the two lower rolls change in time, causing oscillations between the two halves. 
LES

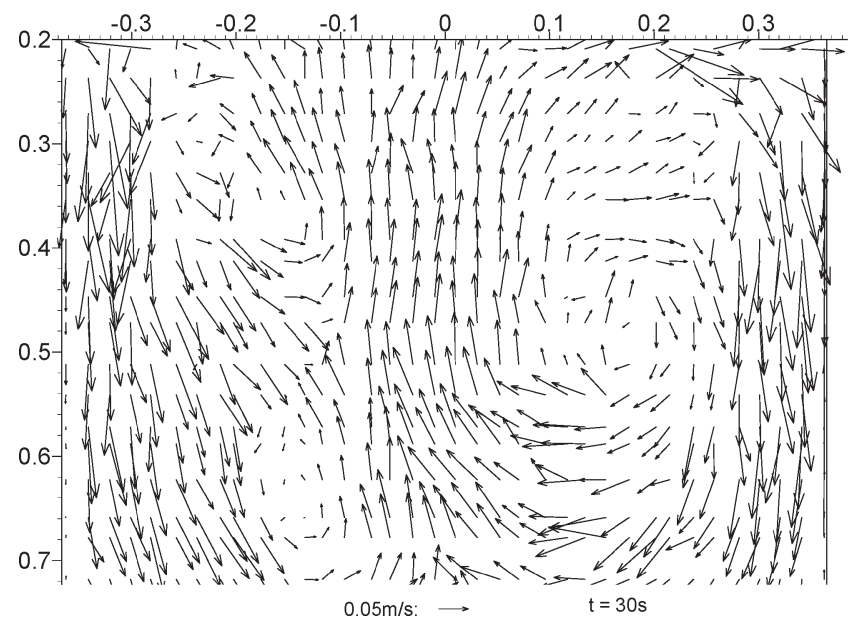

(a)

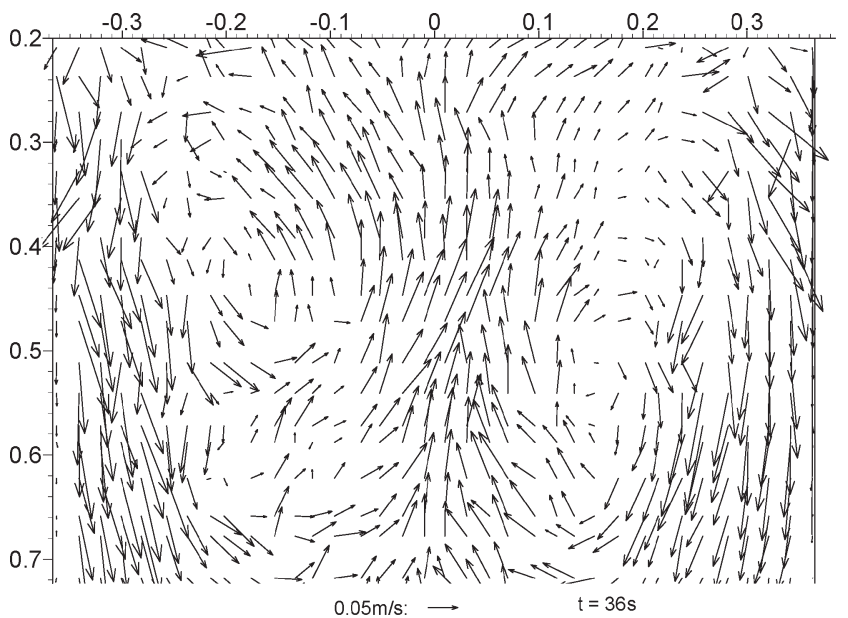

(b)
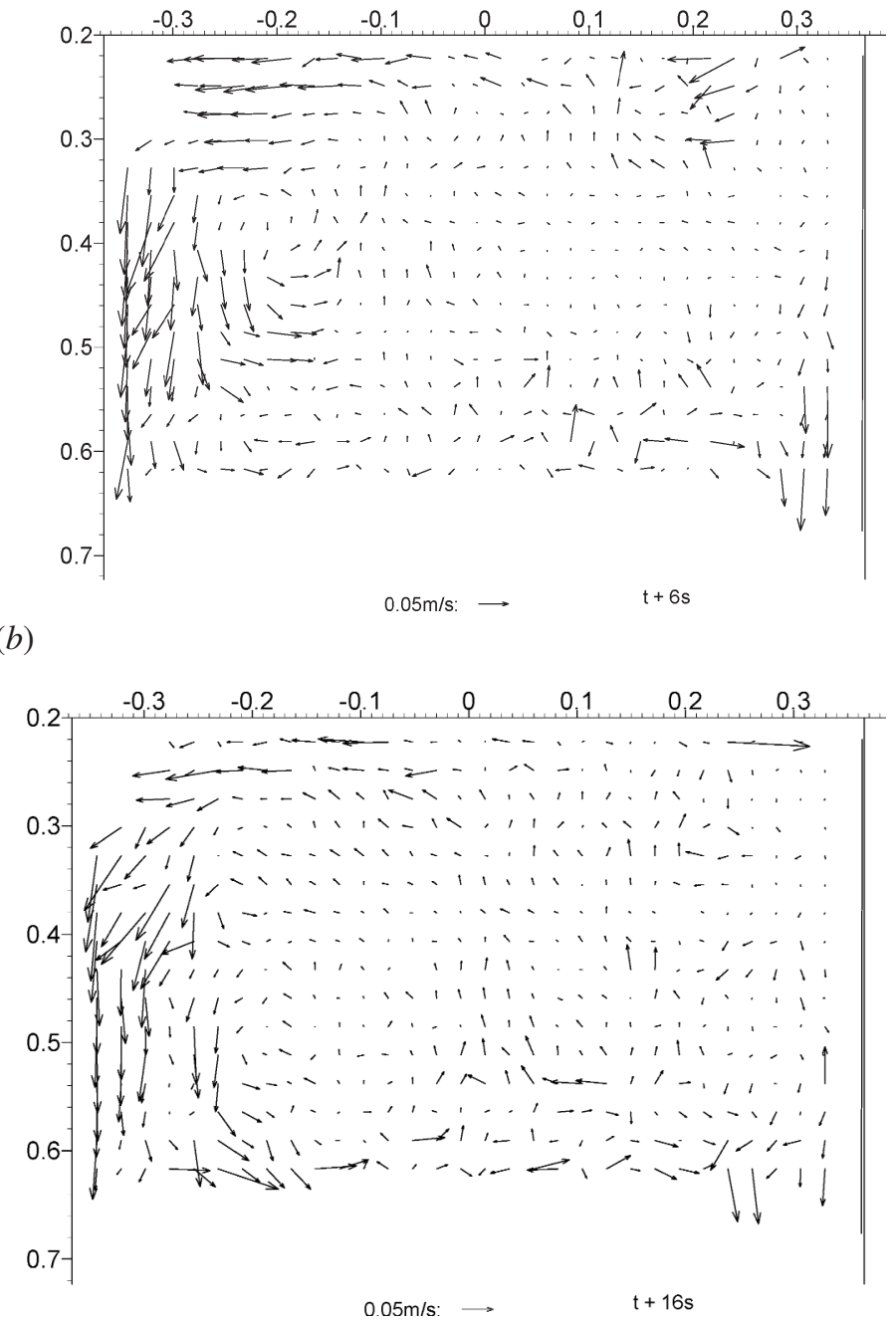

(c)

Fig. 20-A sequence of instantaneous velocity vector plots in the lower roll region obtained from LES and PIV measurements, showing evolution of flow structures.

Asymmetric flow in the two halves is seen in both the computation and measurements. The long-term experimental data implies that the period of the flow asymmetry in the lower region is longer than 200 seconds. The asymmetrical flow structures shown here are likely one reason for the intermittent defects observed in steel slabs. ${ }^{[53]}$ 


\section{SIMPLFIED COMPUTATIONS IN MOLD CAVITY}

Although less expensive than DNS, LES still requires considerable computational resources for applications to industrial problems. The domain of the LES shown earlier includes the complete UTN, the slide gate, the SEN, and the full mold cavity. The computational cost may be lowered by reducing the domain extent, by simplifying the upstream domain that determines the inlet conditions, or by simulating flow in only half of the mold cavity by assuming symmetric flow in the two halves of the mold.

This section presents results of two half-mold simulations with simplified inlet conditions. The curved tapering cavity was simplified to be a straight domain, with a constant thickness equal to the thickness $0.3 \mathrm{~m}$ below the top surface. The timedependent inlet velocities from the nozzle port were obtained from two simplified separate simulations. The results are compared with the complete nozzle-mold simulation and PIV measurements presented earlier.

For the first simplified simulation, the unsteady velocities exiting the nozzle ports were obtained from a two-step simulation. In the first step, turbulent flow in a 32-mm diameter pipe with a 39 pct opening inlet (Figure 21) was computed using LES. Instantaneous velocities were collected every $0.01 \mathrm{sec}-$ ond for 10 seconds at a location $0.312 \mathrm{~m}$ downstream of the inlet. They were then fed into a $32 \times 32$-mm rectangular duct (Figure 21) that represented the flow passage in the nozzle bottom containing the bifurcated nozzle ports. Instantaneous velocities were then collected every 0.01 second for $10 \mathrm{sec}-$ onds a location $27 \mathrm{~mm}$ from the center of the duct. These velocities were turned by $30 \mathrm{deg}$ (to match the measured jet angle) and employed as the unsteady inlet conditions for

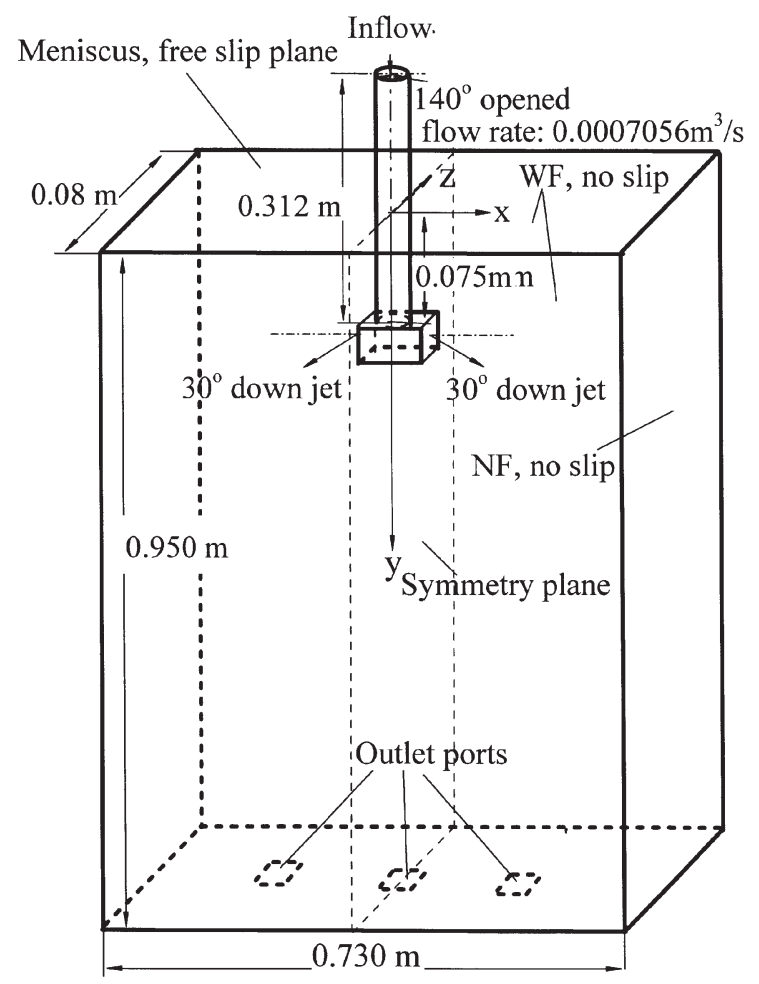

Fig. 21-Schematics showing the simplified simulations of the 0.4-scaled water model. the first mold simulation. The velocities were recycled periodically for the duration of the mold simulation.

For the second simplified simulation, the inlet velocities were computed from a simulation of fully developed turbulent flow in a 32-mm-square duct. The unsteady velocities were again collected every 0.01 second for 10 seconds inclined $30 \mathrm{deg}$, and fed into the mold as the inlet conditions. Figure 22 shows the time-averaged cross-stream inlet velocities for these two simulations. A strong dual-swirl pattern is seen in the outlet plane of the nozzle port in the first simulation (left). The crossstream velocities for the second simulation (right) are very small. Both of the simplified upstream simulations produce inlet conditions different from that in the complete nozzle-mold simulation (Figure 4). Further details on these simulations are given elsewhere. $^{[13]}$

The turbulent flow in the half-mold cavity was next computed using the inlet velocities obtained above. ${ }^{[13]}$ The mean velocity fields at the center plane $(y=0)$ are shown in Figure 23. Both of the plots reveal a double-roll flow pattern similar to the complete nozzle-mold simulation and PIV measurements. Comparisons of the time-averaged velocities in both the upper and lower regions (not shown) also suggest that these two simplified simulations roughly agree with results of the full-mold simulations and PIV. However, a straight jet is observed in the second simulation, which differs from the first simplified simulation, the complete nozzlemold simulation, and the PIV. The lack of cross-stream velocities in the jet is believed to be the reason for the straight jet. Neither of these simplified half-mold simulations captured the instantaneous stair-step-shaped jet observed earlier. Both simulations missed the phenomena caused by the interaction between the flow in the two halves, which is reported to be important to flow transients. ${ }^{[51]}$ Figure 24 illustrates this with sample velocity signals at a point $20 \mathrm{~mm}$ below the top surface, midway from the SEN and the narrow face, compared with PIV. It is observed that both the simplified simulations only capture part of the behavior of the measured signal. The sudden jump of the instantaneous $x$ velocity component, which is reproduced by the full-mold simulation (Figure 13), is missing from both half-mold simulations. This suggests that the sharp velocity fluctuation is caused by the interaction of the flow in the two halves. The selection of the computational domain must be decided based on a full consideration of the available computational resources, the interested flow phenomena (e.g., flow asymmetry) and the desired accuracy.

\section{CONCLUSIONS}

Three-dimensional turbulent flow in a 0.4-scale water model was studied using LES. The computed velocity fields are compared with PIV measurements. The following observations are made from this work.

1. The partial opening of the slide gate induces a long, complex recirculation zone in the SEN. It further causes strong swirling cross-stream velocities in the jets exiting from the nozzle ports. Complex flow structures consisting of single and multiple vortices are seen to evolve in time at the outlet plane of the nozzle port.

2. A downward jet with an approximate inclination of $30 \mathrm{deg}$ is seen in both measurements and simulations. The computed 

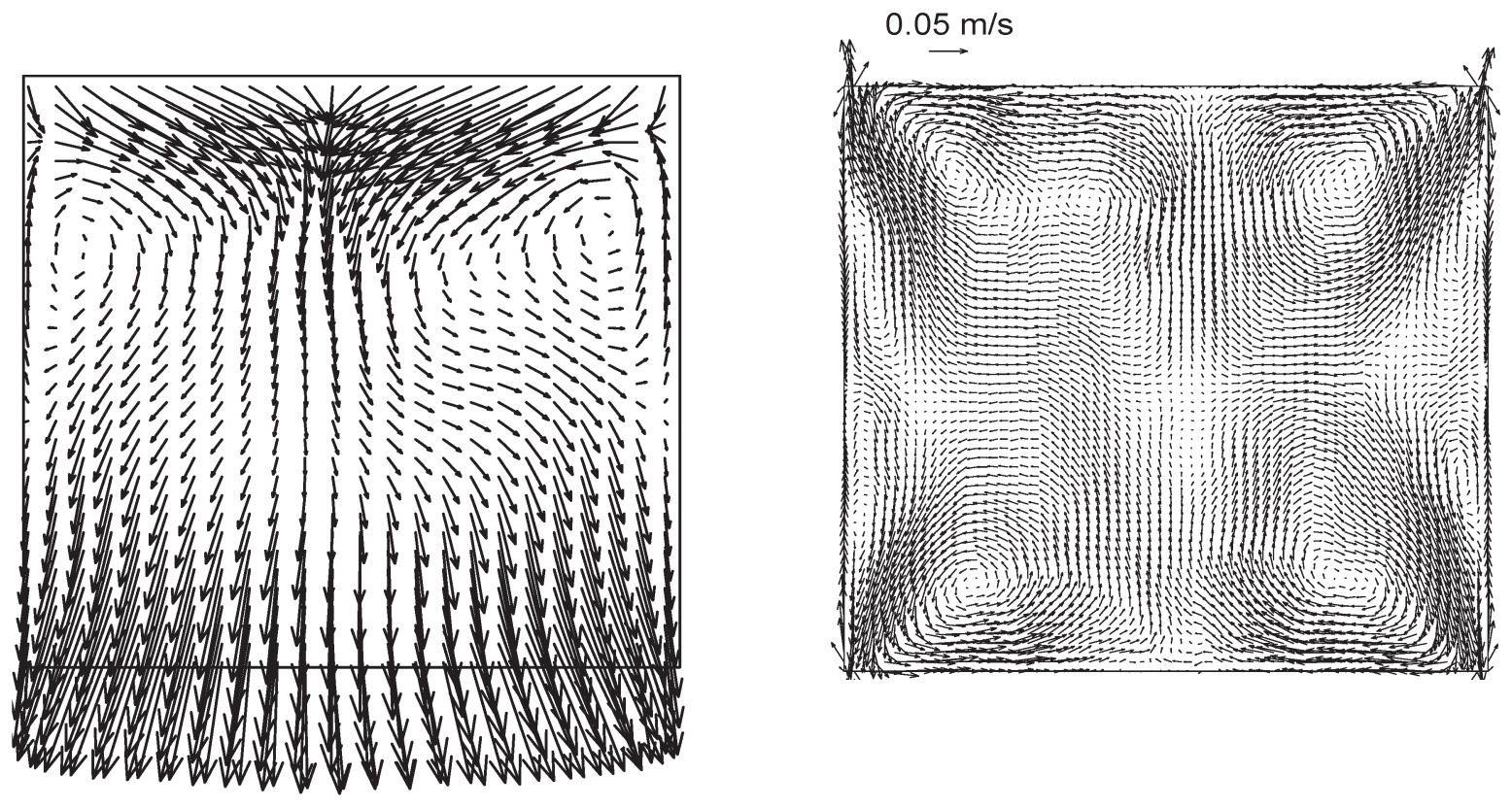

Fig. 22-Cross-stream flow patterns exiting the nozzle port in the simplified simulations.
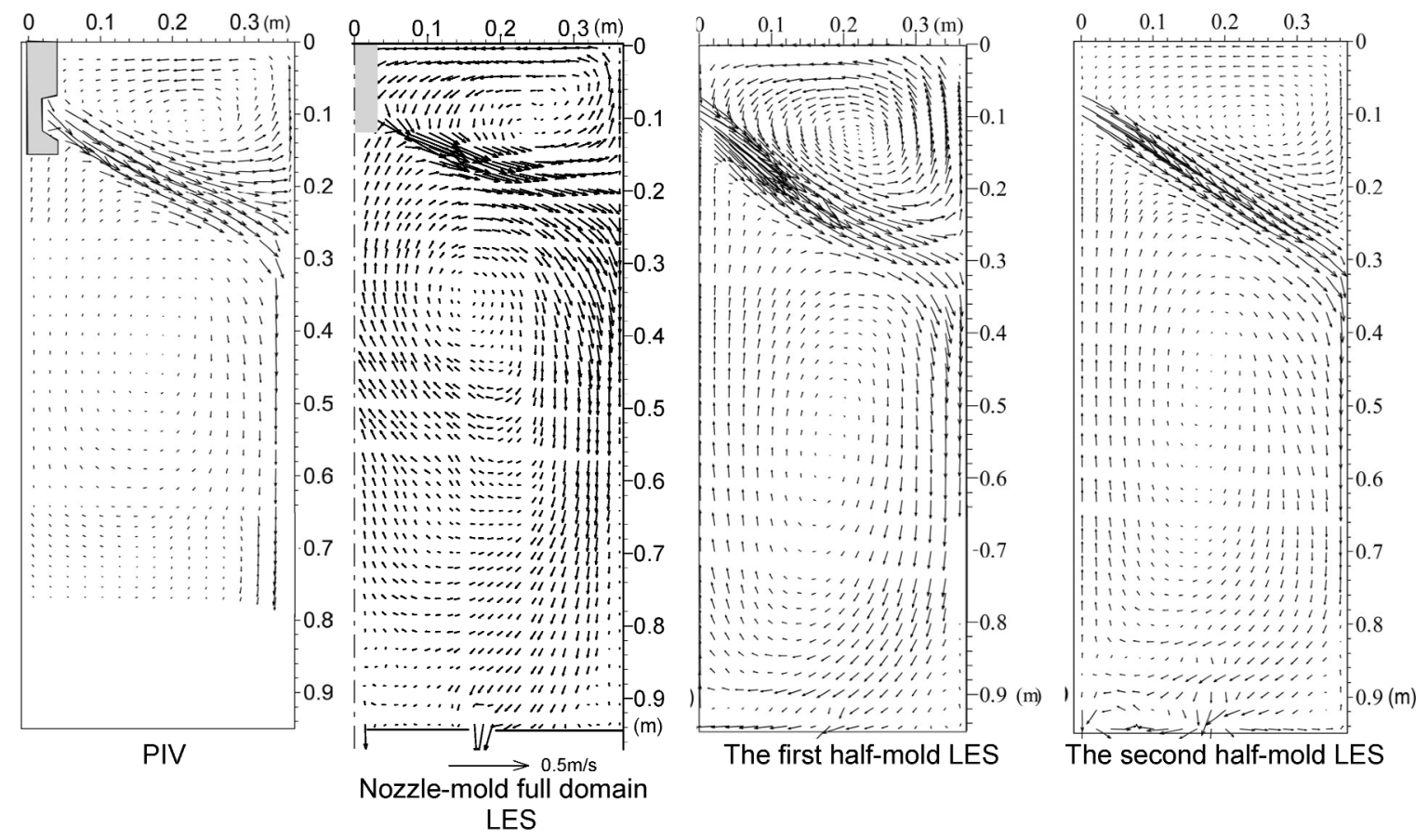

$>0.5 \mathrm{~m} / \mathrm{s}$

Fig. 23-Time-averaged velocity vector plots obtained from the simplified simulations, compared with full nozzle-mold simulation and PIV measurement.

velocities agree reasonably well with measurements in the mold region. The jet usually wobbles with a period of 0.5 to 1.5 seconds.

3. The instantaneous jets in the upper mold cavity alternate between two typical flow patterns: a stair-step-shaped jet induced by the cross-stream swirl in the jet, and a jet that bends upward midway between the SEN and the narrow face. Furthermore, the flow in the upper region is seen to oscillate between a large single vortex and multiple vortices of various smaller sizes. Large, downward-moving vortices are seen in the lower region.

4. Significant asymmetry is seen in the instantaneous flow in the two halves of the mold cavity. A 51-second average reduces this difference in the upper region. However, asymmetric flow structures are seen to persist longer than 200 seconds in the lower rolls. 


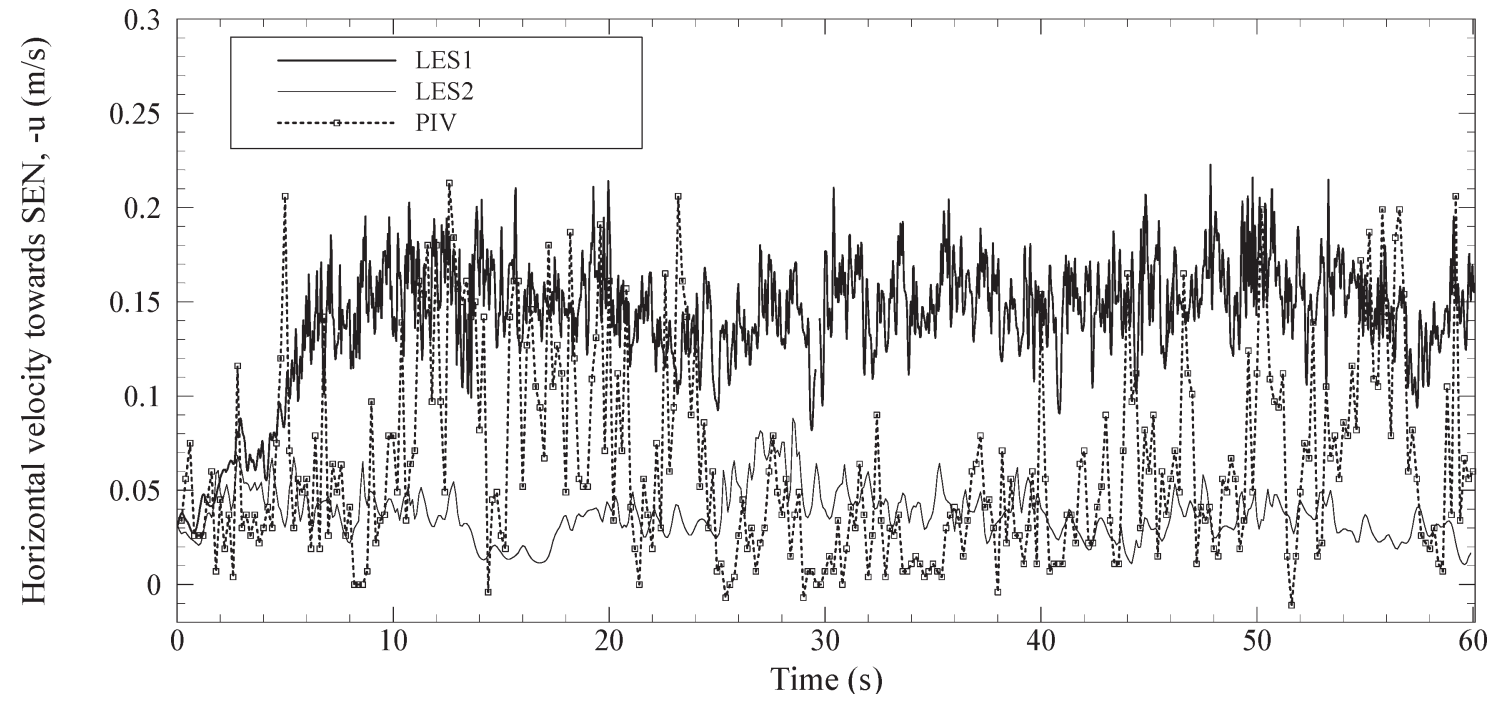

Fig. 24-Time history of horizontal velocity toward SEN at points $20 \mathrm{~mm}$ below the top surface, midway between the SEN and narrow faces.

5. The instantaneous top surface velocity is found to fluctuate with sudden jumps from -0.01 to $0.24 \mathrm{~m} / \mathrm{s}$ occurring in a little as $\sim 0.7$ second. These velocity jumps are seen in both the full nozzle-mold simulations and the PIV measurements. Level fluctuations near the narrow face occur over a wide range of frequencies, with the strongest having periods of $\sim 7$ and 11 to 25 seconds.

6. The velocity fields obtained from half-mold simulations with approximate inlet velocities generally agree with the results of the full domain simulations and PIV measurements. However, they do not capture the interaction between flows in the two halves, such as the instantaneous sudden jumps of top surface velocity.

\section{ACKNOWLEDGMENTS}

The authors thank the National Science Foundation (Grant Nos. DMI-98-00274 and DMI-01-15486), which made this research possible. The work is also supported by the member companies of the Continuous Casting Consortium, University of Illinois at Urbana-Champaign (UIUC). Special thanks are extended to Drs. M.B. Assar and P. Dauby for sharing the PIV data and helpful suggestions, and to the National Center for Supercomputing Applications (NCSA) at UIUC for computational facilities.

\section{NOMENCLATURE}

$\begin{array}{ll}D / D t & \text { total derivative }\left(=\frac{\partial}{\partial t}+v_{j} \frac{\partial}{\partial x_{j}}\right) \\ x_{i} & \text { coordinate direction }(x, y, \text { or } z) \\ v_{i} & \text { velocity component } \\ \nu_{0} & \text { kinematic viscosity of fluid } \\ \nu_{t} & \text { turbulent kinematic viscosity } \\ \nu_{\text {eff }} & \text { effective viscosity of turbulent fluid } \\ \rho & \text { density } \\ p & \text { static pressure } \\ t & \text { time }\end{array}$

$\mathrm{k}_{s g s} \quad$ sub-grid scale turbulent kinetic energy

$\Delta_{i} \quad$ grid size (in $\mathrm{x}, \mathrm{y}$ and $\mathrm{z}$ directions)

Subscript

$i, j \quad$ direction $(x, y, z)$

\section{REFERENCES}

1. L. Zhang and B.G. Thomas: Iron Steel Inst. Jpn. Int., 2003, vol. 43 (3), pp. 271-91.

2. W.H. Emling, T.A. Waugaman, S.L. Feldbauer, and A.W. Cramb: Steelmaking Conf. Proc., Chicago, IL, Apr. 13-16, 1997, ISS, Warrendale, PA, 1994, vol. 77, pp. 371-79.

3. B.G. Thomas: in The Making, Shaping and Treating of Steel, 11th ed., Casting Volume, A.W. Cramb, ed., The AISE Steel Foundation, Warrendale, PA, 2003, p. 24.

4. J. Herbertson, Q.L. He, P.J. Flint, and R.B. Mahapatra: Steelmaking Conf. Proc., ISS, Warrendale, PA, 1991, vol. 74, pp. 171-85.

5. B.G. Thomas, Q. Yuan, S. Sivaramakrishnan, T. Shi, S.P. Vanka, and M.B. Assar: Iron Steel Inst. Jpn. Int., 2001, vol. 41 (10), pp. 1262-71.

6. R. Sobolewski and D.J. Hurtuk: 2nd Process Technology Conf. Proc., ISS, Warrendale, PA, 1982, vol. 2, pp. 160-65.

7. D. Gupta and A.K. Lahiri: Steel Res., 1992, vol. 63 (5), pp. 201-04.

8. D. Gupta and A.K. Lahiri: Metall. Mater. Trans. B, 1996, vol. 27B, pp. 757-64.

9. M.B. Assar, P.H. Dauby, and G.D. Lawson: Steelmaking Conf. Proc., ISS, Warrendale, PA, 2000, vol. 83, pp. 397-411.

10. B.G. Thomas, X. Huang, and R.C. Sussman: Metall. Mater. Trans. B, 1994, vol. 25B, pp. 527-47.

11. B.G. Thomas and L. Zhang: Iron Steel Inst. Jpn. Int., 2001, vol. 41 (10), pp. 1181-93.

12. F.M. White: Viscous Fluid Flow, 2nd ed., McGraw-Hill Series in Mechanical Engineering, McGraw-Hill, Boston, MA, 1991, p. 614.

13. S. Sivaramakrishnan: Master's Thesis, University of Illinois at Urbana-Champaign, Urbana, 2000.

14. Q. Yuan, B.G. Thomas, and S.P. Vanka: Metall. Mater. Trans. B, 2004, vol. 35B, pp. 685-702.

15. E.R.G. Eckert: in Fluid Mechanics Measurements, R.J. Goldstein, ed., Taylor \& Francis, Washington, D.C., 1996, pp. 65-114.

16. R.J. Adrian: in Fluid Mechanics Measurements, R.J. Goldstein, ed., Taylor \& Francis, Washington, D.C., 1996, pp. 175-299.

17. N.J. Lawson and M.R. Davidson: J. Fluids Eng., 2002, vol. 124 (6), pp. 535-43.

18. R.J. Adrian: Annu. Rev. Fluid Mech., 1991, vol. 23, pp. 261-304.

19. I.I. Lemanowicz, R. Gorissen, H.J. Odenthal, and H. Pfeifer: Stahl Eisen., 2000, vol. 120 (9), pp. 85-93. 
20. S.B. Pope: Turbulent Flows, Cambridge University Press, Cambridge, United Kingdom, 2000, p. 771.

21. D.E. Hershey, B.G. Thomas, and F.M. Najjar: Int. J. Num. Meth. Fluids, 1993, vol. 17, pp. 23-47.

22. F.M. Najjar, D.E. Hershey, and B.G. Thomas: 4th FIDAP Users Conf., Evanston, IL, 1991, Fluid Dynamics International, Inc., Evanston, IL, 1991, pp. 1-55.

23. H. Bai and B.G. Thomas: Metall. Mater. Trans. B, 2001, vol. 32B, pp. 253-67.

24. H. Bai and B.G. Thomas: Metall. Mater. Trans. B, 2001, vol. 32B, pp. 269-84.

25. B.G. Thomas, L.M. Mika, and F.M. Najjar: Metall. Trans. B, 1990, vol. 21B, pp. 387-400.

26. M.R. Aboutalebi, M. Hasan, and R.I.L. Guthrie: Metall. Mater. Trans. $B, 1995$, vol. 26B, pp. 731-44.

27. X.K. Lan, J.M. Khodadadi, and F. Shen: Metall. Mater. Trans. B, 1997, vol. 28B, pp. 321-32.

28. X. Huang and B.G. Thomas: Can. Metall. Q., 1998, vol. 37 (304), pp. $197-212$.

29. B.G. Thomas: Mathematical Models of Continuous Casting of Steel Slabs, Report, Continuous Casting Consortium, University of Illinois at Urbana-Champaign, Urbana, IL, 2000.

30. J. Knoepke, M. Hubbard, J. Kelly, R. Kittridge, and J. Lucas: Steelmaking Conf. Proc., Chicago, IL, Mar. 20-23, 1994, ISS, Warrendale, PA, 1994, pp. 381-88.

31. Q. Yuan, S.P. Vanka, and B.G. Thomas: 2nd Int. Symp. on Turbulent and Shear Flow Phenomena, Stockholm, Royal Institute of Technology (KTH), Stockholm, 2001, p. 6.

32. U. Schumann: J. Comput. Phys., 1975, vol. 8, pp. 376-404.

33. K. Horiuti: J. Phys. Soc. Jpn., 1985, vol. 54 (8), pp. 2855-65.

34. H. Schmidt and U. Schumann: J. Fluid Mech., 1989, vol. 200, pp. 511-62.

35. U. Schumann: Theor. Comput. Fluid Dyn., 1991, vol. 2, pp. 279-90.

36. W.W. Kim and S. Menon: AIAA 97-0210, American Institute of Aeronautics and Astronautics (AIAA), New York, NY, 1997.
37. F.H. Harlow and J.E. Welch: Phys. Fluids, 1965, vol. 8 (112), pp. 2182-89.

38. J. Crank and P. Nicolson: Proc. Cambridge Phil. Soc., 1947, vol. 43, pp. 50-67.

39. L.F. Sampine and M.K. Gordon: Computer Solution of Ordinary Differential Equations: the Initial Value Problem, W.H. Freeman \& Co., San Francisco, CA, 1975.

40. Center for Applied Scientific Computing, Lawrence Livermore National Laboratory, Livermore, CA, [Report No. UCRL-MA-137155 DR], 2001.

41. Q. Yuan, B. Zhao, S.P. Vanka, and B.G. Thomas: unpublished research, 2004.

42. R. Madabushi and S.P. Vanka: Phys. Fluids, 1991, vol. 3 (11), pp. 2734-745.

43. H. Tennekes and J.L. Lumley: A First Course in Turbulence, The MIT Press, Cambridge, MA, 1992, pp. 197-222.

44. H. Bai and B.G. Thomas: Metall. Mater. Trans. B, 2001, vol. 32B, pp. 707-22.

45. F.M. Najjar, B.G. Thomas, and D.E. Hershey: Metall. Mater. Trans. B, 1995, vol. 26B, pp. 749-65.

46. H. Bai: Ph.D. Thesis, University of Illinois at Urbana-Champaign, Urbana, IL, 2000.

47. A. Cramb, Y. Chung, J. Harman, A. Sharan, and I. Jimbo: Iron Steelmaker, 1997, vol. 24 (3), pp. 77-83.

48. Q. Yuan, B.G. Thomas, and S.P. Vanka: Metall. Mater. Trans. B, 2004, vol. 35B, pp. 703-14.

49. S. Sivaramakrishnan, H. Bai, B.G. Thomas, P. Vanka, P. Dauby, and M. Assar: Ironmaking Conf. Proc., ISS, Warrendale, PA, 2000, vol. 59, pp. 541-57.

50. D. Gupta and A.K. Lahiri: Metall. Mater. Trans. B, 1994, vol. 25B, pp. 227-33.

51. T. Honeyands and J. Herbertson: 127th ISIJ Meeting, ISIJ, Tokyo, 1994.

52. D. Gupta, S. Chakraborty, and A.K. Lahiri: Iron Steel Inst. Jpn. Int., 1997, vol. 37 (7), pp. 654-58.

53. R. Gass: Inland Steel, Inc., East Chicago, IN, private communication, 1992 